\title{
The Age-Specific Burdens of Short-Run Fluctuations in Government Spending
}

\author{
Burkhard Heer ${ }^{a, b}$ and Christian Scharrer ${ }^{a}$
}

\author{
${ }^{a}$ University of Augsburg, Department of Economics, Universitätsstrasse 16, 86159 \\ Augsburg, Germany. E-mail: burkhard.heer@wiwi.uni-augsburg.de, \\ christian.scharrer@wiwi.uni-augsburg.de \\ ${ }^{b}$ CESifo, Munich, Germany.
}

Date: January 30, 2019

JEL classification: E62, E30, E12, E24, D31

Key Words: Fiscal Policy, Debt Financing, Income and Wealth Distribution, Ruleof-Thumb Consumers, Ricardian Households, Overlapping Generations

\begin{abstract}
:
We study the impact of government spending shocks on the distribution of income and wealth between cohorts and the associated welfare effects in a dynamic stochastic overlapping generations model with two types of households, Ricardian households and rule-of-thumb consumers. We demonstrate that an unexpected increase in government spending decreases income and wealth inequality. In contrast to the conventional wisdom that the financing of government expenditures by debt rather than taxes especially burdens young generations, we find that debt-financing also harms Ricardian households during retirement. The crucial element in our analysis is a wealth effect that results from the decline in the price of capital due to higher government debt.
\end{abstract}

We would like to thank Santanu Chatterjee, Thomas Lubik, Stephen Turnovsky, Johann Scharler, Andreas Pollak, and two anonymous referees for helpful comments. All remaining errors are ours. 


\section{Introduction}

The distributional consequences of higher government spending between different generations constitute a major concern for economic policy in modern industrialized countries. The appropriate fiscal rule, which controls the response of taxes and government debt if government consumption changes, plays a crucial role in this regard. A positive government spending shock financed by bonds transfers a real economic burden on present young or even future generations, whereas a tax-financed increase in government spending shifts the burden into the present. In this paper, we study the associated effects of unanticipated short-run fluctuations in government spending on inequality and welfare in a New Keynesian stochastic overlapping generations (OLG) model that both replicates the wealth and income distribution in the US and accords well with empirical evidence from VAR studies.

Our main results show, in particular, that a positive government spending shock marginally decreases the inequality of gross market income and wealth with nontrivial redistributive effects on the disaggregate level which are not captured by aggregate measures of inequality like the Gini coefficient. Moreover, and contrary to the conventional wisdom, we find that debt financing of government expenditures may also harm a large fraction of the elderly with asset holdings. Debt financing causes stronger fluctuations in asset prices and, hence, welfare, while tax financing allows households to better smooth their consumption over the life-cycle in response to government spending shocks.

Our New Keynesian model features overlapping generations with two types of households, Ricardian households who save for old age and rule-of-thumb consumers who do not accumulate any wealth. ${ }^{1}$ Furthermore, we introduce workers with different productivity types and particularly incorporate a labor income tax function pro-

\footnotetext{
${ }^{1}$ Rule-of-thumb consumers have been prominently introduced in the business cycle analysis by Galí et al. (2007). They show that, in the presence of rule-of-thumb consumers, the standard New Keynesian model is able to replicate a rise of private consumption in response to an unexpected increase in government consumption.
} 
posed by Benabou (2002) such that we are also able to take into account the most important redistributive features of the US tax system and its effects on inequality. These assumptions allow us to replicate the empirically observed high concentration of wealth and the somewhat smaller concentration of income by quintile groups in the US. The Gini coefficients of wealth and gross income in our model amount to 0.789 and 0.573 , respectively, which are broadly consistent with evidence presented by Budría Rodríguez et al. (2002). ${ }^{2}$

In addition, we introduce an investment goods sector that results in a variable price of capital. In this setting, a debt-financed increase in government spending leads to a larger crowding-out effect on productive private investment than a tax-financed increase. The real price of capital decreases strongly and partially transmutes into an additional negative wealth shock affecting the wealth accumulation and consumption decisions of workers and retirees. Retired Ricardian households are completely exposed to this shock because they have accumulated considerable wealth and cannot increase their labor supply in order to benefit from higher wages. There are two opposing effects of higher government consumption on inequality in our model. 1) Higher wages have a stronger incentive effect on the labor supply of high-productivity workers than on the labor supply of low-productivity workers so that gross labor income becomes more concentrated. 2) Since the price of capital and interest rates decline, capital income, however, falls. The overall effect on the income distribution is that inequality measured by the Gini coefficient declines to a small extent. Moreover, wealth inequality also falls slightly with higher government consumption since the price of capital decreases. Therefore, the values of the existing wealth holdings decline, while it becomes more beneficial to build up savings for the less affluent younger cohorts.

The main wealth channel in our model - higher government consumption crowds out capital and decreases the value of wealth - is supported by empirical evidence. In particular, we find that positive fiscal policy shocks induce a temporary fall in

\footnotetext{
${ }^{2}$ Budría Rodríguez et al. (2002) report Gini coefficients of wealth and (gross) income equal to 0.803 and 0.553 .
} 
stock prices in our model. This result is in accordance with findings from previous empirical studies. For example, Afonso and Sousa (2012) and Agnello and Sousa (2013) provide empirical evidence that a positive fiscal policy shock leads to an immediate and negative response of stock prices influencing the wealth of different cohorts. In addition, real interest rates decline in our model as a consequence of the decrease in capital prices. With respect to the effect of government spending on real interest rates, the empirical evidence is more mixed. On the one hand, Ramey and Shapiro (1998) and Fatás and Mihov (2001) provide empirical evidence that real T-bill rates increase after a positive government spending shock. But, on the other hand, more recent studies such as Fisher and Peters (2010) and even Ramey (2011) find a negative (transient) effect of government spending on real interest rates. Murphy and Walsh (2016) survey the literature on this topic and provide additional empirical evidence for declining interest rates. They come to the conclusion that most studies with US data usually support a negative relationship.

Our New Keynesian model is also broadly consistent with empirical evidence from VAR studies. In particular, an increase of government spending results in 1) an increase of output ${ }^{3}$ and 2) private consumption, ${ }^{4} 3$ ) a strong decline in investment and the price of capital, 4) higher employment, ${ }^{5} 5$ ) higher wages, ${ }^{6}$ and 6) lower markups. $^{7}$ The presence of rule-of-thumb consumers helps to reconcile the model with the

\footnotetext{
${ }^{3}$ Blanchard and Perotti (2002) provide evidence for the US postwar economy that GDP increases after an expansion of fiscal spending. Using panel structural VAR analysis from four industrialized countries, Ravn et al. (2012) also provide cross-country evidence for this hypothesis.

${ }^{4}$ There is some mixed evidence with regard to the effect of government consumption increases on private consumption. The prevalent view, however, indicates a positive effect of higher government consumption as in the studies presented by, for example, Blanchard and Perotti (2002), Galí et al. (2007), and Ravn et al. (2012).

${ }^{5}$ See, for example, Blanchard and Perotti (2002).

${ }^{6}$ Here, again, the empirical evidence is mixed. Rotemberg and Woodford (1992) present evidence that real wages also increase after a government spending shock, while Monacelli et al. (2010) only find an statistically insignificant rise of the real wage for men.

${ }^{7}$ Again, Monacelli et al. (2010) only find evidence for a decline of the mark-ups that is statistically
} 
data and to effectuate the observed responses of output, employment, consumption, and wages. Since rule-of-thumb consumers are not subject to a wealth effect from higher government consumption, their labor supply curve shifts out less than that of the Ricardian households. As a consequence, there is more upward pressure on the real wage. In addition, higher wages allow for an increase of consumption. In the absence of rule-of-thumb consumers, we do not find an increase of aggregate private consumption in response to higher government spending.

The study most closely related to ours is provided by Chatterjee and Turnovsky (2012) who analyze the effects of an unanticipated permanent increase of public infrastructure spending in a general equilibrium growth model with heterogeneous agents. Heterogeneity is thereby introduced in the form of unequal levels of individuals' initial wealth. They find that, irrespective of the financing form via distortionary or lump sum taxes, wealth inequality increases along the transition path, whereas income inequality declines on impact. In contrast, we focus on the shortrun fluctuations in government spending over the business cycle and the associated effects on inequality and welfare. Moreover, Brinca et al. (2016) study the effects of wealth inequality and the average wealth level on fiscal multipliers. In a sample of 15 OECD countries, they find that fiscal multipliers increase with the country Gini of wealth and decrease with the capital-output ratio. The regression coefficients in their SVARs are quantitatively significant and an increase of one standard deviation in the wealth Gini raises the multiplier by about $17 \%$ of the average multiplier value. Similar to our model, their overlapping generations model is able to replicate the empirically observed heterogeneity in income and wealth. While Brinca et al. (2016) also include uncertainty with regard to idiosyncratic productivity, we focus on aggregate uncertainty in the form of stochastic government spending. In related but independent research, Ferriere and Navarro (2016) also analyze a heterogeneousagent economy and the effects of unanticipated government spending. However, their model is an extension of the Aiyagari (1994) model where individuals have infinite 
lifetime. ${ }^{8}$ They are also successful in matching the empirical observation that aggregate output and consumption increase after an unanticipated increase in government spending with their model. In order to derive this results, two key assumptions are necessary. First, individual labor is indivisible. Second, labor income taxes are progressive, and progressivity increases in times of higher government spending.

While Chatterjee and Turnovsky (2012), Brinca et al. (2016), and Ferriere and Navarro (2016) abstract from any nominal friction, we consider a New Keynesian model with sticky prices. Our model is able to generate a positive response of private consumption (and output) to an increase in government consumption even in the case of flexible labor supply and constant labor income tax progressiveness. To the best of our knowledge, there exist no other studies of government spending shocks in DSGE models with an overlapping generations structure that consider a variable price of capital, which is a vital and necessary assumption for the derivations of our main results.

Our study is also related to the literature on tax-smoothing. In his seminal paper, Barro (1979) argues that the government should smooth taxes and use debt to finance deficits in times of higher government spending. In his model, distortionary income taxes are the only departure from non-Ricardian equivalence. Since the distortions rise non-linearly with the tax rate, a constant tax over time increases welfare. In contrast, we find in our model that tax-financing implies higher welfare gains than debt-financing so that income taxes should fluctuate (to a certain extent) over time. Our model differs from the one in Barro (1979) in several aspects. First,

\footnotetext{
${ }^{8}$ Chang et al. (2016) extend the Aiyagari model with endogenous labor in order to study the effects of higher (redistributive) income taxes on income inequality in a political economy. In their model, they consider the effect of a binary vote between the present and the optimal income tax (the one that maximizes expected lifetime utility) and demonstrate that, in most OECD countries, a majority would support the latter. In the empirical part of their paper, they show that higher taxes reduce income inequality in OECD countries. While their focus is on the long-run analysis of fiscal policy, we consider unanticipated temporary shocks.
} 
government spending is stochastic. ${ }^{9}$ Second, we introduce New Keynesian elements in the form of price staggering and an endogenous price of capital into our model. And third, we implement two additional non-Ricardian elements in the form of finite lifetime and rule-of-thumb consumers. Therefore, Ricardian Equivalence does not hold and government spending crowds out investment in our model. Implementing the first two model elements and studying the implications in a representative-agent economy, Schmitt-Grohé and Uribe (2006) show that the optimal fiscal feedback rule is pro-cyclical in this case. Consequently, if government consumption and, hence, output increase, then taxes should also rise. ${ }^{10}$ We find the same result in our model and confirm its robustness with respect to its extension to a non-Ricardian economy where fiscal policy redistributes between generations and between Ricardian and non-Ricardian household types.

The rest of our paper is organized as follows: Section 2 introduces the model. In Section 3, we calibrate the non-stochastic steady state of our model and explain the algorithm used for the numerical computation. In Section 4, we characterize the steady state and the associated distribution of consumption, income, wealth, and labor supply over the life-cycle. Section 5 presents our main results with regard to the effects of an unanticipated temporary increase in government spending on the distribution of wealth and disposable income on the one hand and the welfare of the different cohorts, productivity types, and consumers (Ricardian versus rule-of-thumb consumers) on the other hand. We contrast the effects of a debt-financed increase in government expenditures with those of a tax-financed increase. In Section 6, we summarize and discuss the main findings of the paper and point out directions for future research.

\footnotetext{
${ }^{9}$ In this case, Barro's model implies that the optimal tax should follow a random walk.

${ }^{10}$ Luo et al. (2014) introduce Bayesian agents into the standard Barro (1979) model who are concerned about the possibility that their true model is misspecified. In this case, a departure from tax smoothing is also optimal. The authors demonstrate that their model is able to replicate the correlation of government deficits and spending.
} 


\section{The Model}

We use an overlapping generations model with 240 generations and aggregate uncertainty. The period length is set to one quarter. The Ricardian equivalence does not hold in our model so that the financing of government spending has real effects. The economy consists of households, firms, a government sector, and a monetary authority. We distinguish two types of households. The first kind of households, which we name Ricardian households, solves an inter-temporal maximization problem, while the second type behaves as a rule-of-thumb consumer. The firm sector is composed of three types of firms. A perfectly competitive firm produces a single final good and employs differentiated intermediate goods as inputs. These inputs are produced by a continuum of monopolistic competitive firms which use capital and labor in their production process. In addition, there is a capital producer that transforms investments (in terms of the final good) into new capital. The government both collects taxes and accidental bequests and issues risk-less bonds in order to finance its government purchases. The monetary authority monitors the inflation rate and sets the nominal interest rate according to a simple Taylor rule.

In the following, we first describe the demographics. Next, we specify the production sectors of the economy. A final good is manufactured from intermediate goods and is used for both consumption and as input into the production of a separate capital good. The rate of return on capital depends on the utilization rate of capital $u_{t}$ and is a composite of multiple rates since capital is first used in the production of the intermediate good (over the whole period $t$ ) before it is rented to the capital producers at the end of period $t$. Finally, we describe the behavior of the households who also choose the utilization rate of capital $u_{t}$ (see Christiano et al. (2005)).

\subsection{Demographics}

Every period, a new cohort of constant size at age $s=1$ (corresponding to a real life age of 20) enters the economy. Households live at most $T=240$ quarters and each $s$-year old household faces a probability $\phi_{s}$ of surviving up to age $s+1$. More 
precisely, the parameter $\left(1-\phi_{s}\right)$ denotes the probability of dying at the end of age $s$. The number of living agents $\psi_{s, t}$ at age $s$ in period $t$ evolves according to the following formula:

$$
\psi_{s+1, t+1}=\phi_{s, t} \psi_{s, t}
$$

where $\phi_{0, t}$ is exogenously given. For simplification, we normalize the total number of living households $\sum_{s=1}^{T} \psi_{s, t}$ to one and assume that the composition of the population remains constant so that we can set $\psi_{s, t}=\psi_{s}$.

\section{$2.2 \quad$ Firms}

\subsubsection{Final Goods Firms}

There is a representative, perfectly competitive firm which produces a final good $Y_{t}$ using a constant returns to scale technology:

$$
Y_{t}=\left(\int_{0}^{1} Y_{i, t}^{(\epsilon-1) / \epsilon} \mathrm{d} i\right)^{\epsilon /(\epsilon-1)} .
$$

This firm assembles the imperfectly substitutable output $Y_{i, t}$ of intermediate producers and takes the price $P_{t}$ of the final good $Y_{t}$ as well as the prices $P_{i, t}$ of intermediary products as given. Moreover, $i \in[0,1]$, and $\epsilon$ denotes the price elasticity of demand for good $i$. After maximizing the profit function, $P_{t} Y_{t}-\int_{0}^{1} P_{i, t} Y_{i, t} \mathrm{~d} i$, with respect to $Y_{i, t}$, we can derive the following demand function for intermediary goods:

$$
Y_{i, t}=\left(\frac{P_{i, t}}{P_{t}}\right)^{-\epsilon} Y_{t}
$$

Furthermore, the zero-profit condition in a perfectly competitive market implies

$$
P_{t}=\left(\int_{0}^{1} P_{i, t}^{1-\epsilon} \mathrm{d} i\right)^{1 /(1-\epsilon)} .
$$

\subsubsection{Intermediate Goods Firms}

The intermediate goods sector consists of a continuum of monopolistic firms indexed by $i \in[0,1]$. Each firm $i$ uses effective capital $u_{t} K_{i, t}$ and labor $N_{i, t}$ as input factors. 
The production technology is identical across firms and takes the form

$$
Y_{i, t}=N_{i, t}^{1-\alpha}\left(u_{t} K_{i, t}\right)^{\alpha}-F, \quad \alpha \in(0,1), F>0 .
$$

The constant $F$ denotes a fixed cost and can be considered as a loss of output in the production process. The utilization rate $u_{t}$ is considered as exogenous by the firm and will be set by the Ricardian households who rent the capital stock (in efficiency units) to the firm (see also next section).

Each firm sets prices according to a Calvo (1983) mechanism. However, it is more appropriate to solve the firm's cost minimization problem first, where $r_{t}^{i s}$ is the real interest rate in the intermediate goods sector and $w_{t}$ is the real wage:

$$
\min _{u_{t} K_{i, t}, N_{i, t}} C_{i, t}=w_{t} N_{i, t}+r_{t}^{i s} u_{t} K_{i, t} \text { s.t. } Y_{i, t}=N_{i, t}^{1-\alpha}\left(u_{t} K_{i, t}\right)^{\alpha}-F
$$

The first-order conditions of this cost-minimization problem with respect to $N_{i, t}$ and $u_{t} K_{i, t}$ are presented by:

$$
\begin{aligned}
& w_{t}=(1-\alpha) g_{i, t}\left(\frac{u_{t} K_{i, t}}{N_{i, t}}\right)^{\alpha}, \\
& r_{t}^{i s}=\alpha g_{i, t}\left(\frac{u_{t} K_{i, t}}{N_{i, t}}\right)^{\alpha-1},
\end{aligned}
$$

where $g_{i, t}$ denotes the Lagrange multiplier which also describes the real marginal cost of production. Moreover, since we assume that the production of $Y_{i, t}+F$ is characterized by a constant returns to scale technology, the variable $g_{i, t}$ also equals the variable unit costs of production. The first-order conditions (6a) and (6b) imply that marginal costs are equal across all firms, since every firm uses the same capitallabor ratio. Thus, we can drop the index $i, g_{t}=g_{i, t}$ for all $i \in[0,1]$.

Price setting. Firms choose their optimal nominal prices in a staggered fashion, according to Calvo (1983). There are two types of firms. The first type $A$ sets their optimal relative price by solving an inter-temporal profit optimization problem, whereas type $N$ firms are only allowed to adjust their price in period $t$ according to a simple rule of thumb:

$$
P_{N, t+1}=\pi P_{N, t}
$$


where $\pi$ denotes the stationary value of the inflation factor. ${ }^{11}$ The probability of being a firm of type $A$ in period $t$ is given by $(1-\varphi)$. The description of the optimal price setting is delegated to the Appendix A.1.1.

Real Wage Rigidity. We introduce a real wage rigidity following Hall (2005): ${ }^{12}$

$$
w_{t}=\left(w_{t-1}\right)^{\mu}\left(w_{t}^{f}\right)^{1-\mu}
$$

where $\mu \geq 0$ and the term $w_{t}^{f}$ denotes the marginal rate of substitution between consumption and hours, which we specify in equation (24b) of the household optimization problem.

\subsubsection{Capital Producers}

In the following, we introduce capital adjustment costs in the model so that the price of capital in units of the final goods is variable. By this device, we are able to study the impact of government financing on capital prices and, hence, individual wealth. To keep the model tractable, adjustment costs accrue in a separate capital production sector rather than at the individual household level. For this reason, we assume a representative perfectly competitive firm that faces the following demand for newly installed capital:

$$
I_{t}=K_{t+1}-(1-\delta) K_{t}
$$

The variables $K_{t}$ and $I_{t}$ denote the existing aggregate capital stock and aggregate investment. The production of the investment good is described by the following technology:

$$
I_{t}=f\left(I_{t}^{D} / K_{t}\right) K_{t}
$$

\footnotetext{
${ }^{11}$ Here and in the following, we express stationary variables without a time index.

${ }^{12}$ Krause and Lubik (2007) and Christoffel et al. (2009), among others, have subsequently demonstrated that this kind of real-wage rigidity helps to significantly improve the explanation of the inflation dynamics and the transmission of monetary policy in New Keynesian business cycle models.
} 
with

$$
f\left(I_{t}^{D} / K_{t}\right)= \begin{cases}\frac{a_{1}}{1-\zeta}\left(\frac{I_{t}^{D}}{K_{t}}\right)^{1-\zeta}+a_{2}, & \text { for } 1 \neq \zeta>0 \\ a_{1} \ln \left(\frac{I_{t}^{D}}{K_{t}}\right)+a_{2}, & \text { for } \zeta=1 .\end{cases}
$$

The variable $I_{t}^{D}$ denotes the demand for final goods as input factors in the production process of $I_{t}$ and $1 / \zeta$ is the elasticity of $I_{t} / K_{t}$ with respect to the price of capital goods $q_{t}$. The capital producers sell the investment goods and rent capital at the rate $r_{t}^{c s}$ so that profits of capital producers $\Omega_{t}^{c}$ are given by:

$$
\max _{I_{t}^{D}, K_{t}} \Omega_{t}^{c}=q_{t} f\left(I_{t}^{D} / K_{t}\right) K_{t}-I_{t}^{D}-r_{t}^{c s} K_{t}
$$

Profit maximization of the capital producers with respect to $I_{t}^{D}$ and $K_{t}$ results in the following first-order conditions:

$$
\begin{aligned}
q_{t} & =\frac{1}{f^{\prime}\left(I_{t}^{D} / K_{t}\right)}=\frac{1}{a_{1}}\left(\frac{I_{t}^{D}}{K_{t}}\right)^{\zeta}, \\
r_{t}^{c s} & =q_{t}\left(f\left(I_{t}^{D} / K_{t}\right)-f^{\prime}\left(I_{t}^{D} / K_{t}\right) \frac{I_{t}^{D}}{K_{t}}\right) .
\end{aligned}
$$

In equilibrium, profits are equal to zero, $\Omega_{t}^{c}=0$. Moreover, we set the parameters $a_{1}$ and $a_{2}$ in equation (11) so that adjustment costs play no role in the steady state of the model. ${ }^{13}$

\subsection{Households}

The households supply labor in the first $T_{w}=160$ periods and retire during the remaining $T_{r}=80$ periods of their life. Every newborn generation consists of $v_{R o T} \psi_{1}$ rule-of-thumb (RoT) consumers that have no access to financial markets over the life-cycle ${ }^{14}$ and $\left(1-v_{R o T}\right) \psi_{1}$ Ricardian households, where the fraction $v_{R o T}$ of rule-

\footnotetext{
${ }^{13}$ See Appendix A.1.2.

${ }^{14}$ The behavior of the rule-of-thumb consumers can be justified by a lack of access to financial markets, binding borrowing constraints, myopia, or simply no interest in inter-temporal trading. We follow Galí et al. (2007).
} 
of-thumb-consumers is exogenously given. The household does not change its type over the life-cycle.

In addition to their consumption behavior, households also differ with respect to their idiosyncratic productivity level $e_{j}^{s}$ that depends on the productivity type $j \in$ $\{1,2,3\}$ and age $s$. We assume that the share $v_{j}$ of the productivity type $j$ remains constant in each cohort and that a household does not change its productivity type $j$ over the life-cycle. As a consequence, the gross wage income in period $t$ of the Ricardian household, for example, is given by $w_{t} e_{j}^{s} n_{t, j}^{s}$, where $w_{t}$ and $n_{t, j}^{s}$ denote the wage rate per efficiency unit and the labor supply of the $s$-year-old Ricardian household with productivity type $j$.

We describe the behavior of Ricardian and rule-of-thumb households in turn.

\subsubsection{Ricardian Households}

The Ricardian household with productivity type $j \in\{1,2,3\}$ maximizes the following discounted expected lifetime utility at the beginning of period $t$ :

$$
U_{t, j}=E_{t} \sum_{s=1}^{T} \beta^{s-1}\left(\prod_{j=1}^{s} \phi_{j-1}\right) u\left(c_{t+s-1, j}^{s}, n_{t+s-1, j}^{s}\right) .
$$

Instantaneous utility $u\left(c_{t, j}^{s}, n_{t, j}^{s}\right)$ is a function of consumption $c_{t, j}^{s}$ and labor $n_{t, j}^{s}$ :

$$
u\left(c_{t, j}^{s}, n_{t, j}^{s}\right)=\frac{\left(c_{t, j}^{s}\right)^{1-\eta}-1}{1-\eta}-\gamma_{0} \frac{\left(n_{t, j}^{s}\right)^{1+\gamma}}{1+\gamma},
$$

where $1 / \eta$ and $1 / \gamma$ denote the intertemporal elasticity of substitution and the Frisch labor supply elasticity, respectively. For the retired household at age $s>T_{w}$, labor supply is equal to zero, $n_{t, j}^{s} \equiv 0$.

The Ricardian household with productivity type $j$ holds two kinds of assets, capital stock $k_{t, j}^{s}$ and government bonds $b_{t, j}^{s}{ }^{15}$ Furthermore, we assume that the initial

\footnotetext{
${ }^{15}$ For analytical convenience, we set up the model in terms of the real value of beginning-of-period bond holdings and define $b_{t, j}^{s} \equiv x_{t, j}^{s} / P_{t-1}$, where $x_{t, j}^{s}$ denotes the corresponding nominal bond holdings.
} 
endowment with assets is zero at age $s=1, k_{t, j}^{1}=b_{t, j}^{1}=0$. Let $q_{t}$ denote the price of capital. The capital stock $k_{t}^{s}$ yields the real return $r_{t}$ and depreciates at rate $\delta$ :

$$
r_{t}=r_{t}^{i s} u_{t}+r_{t}^{c s}-\delta\left(u_{t}\right) q_{t}+\frac{\Omega_{t}}{K_{t}}
$$

We assume that the household first lends his capital stock in efficiency units, $u_{t} k_{t, j}^{s}$, to the intermediate goods firms over the period $t$. At the beginning of period $t$, the household also decides about the utilization rate $u_{t} \cdot{ }^{16}$ At the end of the period $t$, the intermediate goods firms pay the return $r_{t}^{i s}$ to the household and capital depreciates at the rate $\delta$ depending on the utilization rate $u_{t}$ :

$$
\delta\left(u_{t}\right)=\delta_{0}+\delta_{1} u_{t}^{1+\epsilon_{u}}
$$

where $\epsilon_{u}$ is the elasticity of the depreciation rate with respect to the utilization rate. The parameters $\delta_{0}$ and $\delta_{1}$ are positive constants. ${ }^{17}$ Since the value of the capital amounts to $q_{t} k_{t, j}^{s}$, the depreciation cost per unit of capital amounts to $\delta\left(u_{t}\right) q_{t}$. In addition, capital owners receive their share in total profits in the intermediate goods sector $\frac{\Omega_{t}}{K_{t}} k_{t, j}^{s}$, where $K_{t}$ denotes aggregate capital. Subsequently, the household lends the capital stock to the capital goods producers and earns the interest $r_{t}^{c s}$. The gross interest rate on capital $R_{t}$ is, therefore, a composite of multiple returns and depends on the price of capital:

$$
R_{t}=\frac{q_{t}+r_{t}}{q_{t-1}}
$$

Furthermore, the term $R_{t}^{b}$ describes the nominal gross interest rate on bonds. Hence, the price of government bonds $b_{t+1, j}^{s}$ is denoted by $1 / R_{t}^{b}$ so that total assets of the individual Ricardian households with productivity type $j$ and age $s$ are presented

\footnotetext{
${ }^{16}$ Since the first-order conditions of the households with respect to the utilization rate are identical and imply the same utilization rate for all households, we drop the indices $j$ and $s$ from the utilization rate $u_{t, j}^{s}$.

${ }^{17}$ See also Appendix A.1.3.
} 
by:

$$
a_{t+1, j}^{s+1} \equiv q_{t} k_{t+1, j}^{s+1}+\frac{b_{t+1, j}^{s+1}}{R_{t}^{b}}
$$

Let $A_{t+1}=q_{t} K_{t+1}+\frac{B_{t+1}}{R_{t}^{b}}$ and $\chi_{t+1}$ denote total assets and the fraction of capital holdings in total assets, respectively, with:

$$
\chi_{t+1}=\frac{q_{t} K_{t+1}}{A_{t+1}} .
$$

Since both assets will yield the same expected return in equilibrium, the household will be indifferent with respect to his portfolio allocation on government bonds $b_{t, j}^{s}$ and capital $k_{t, j}^{s}$. We, therefore, assume that all Ricardian households hold these two assets in the same proportion implying: ${ }^{18}$

$$
\begin{aligned}
& b_{t+1, j}^{s+1}=R_{t}^{b}\left(1-\chi_{t+1}\right) a_{t+1, j}^{s+1}, \\
& k_{t+1, j}^{s+1}=\frac{\chi_{t+1}}{q_{t}} a_{t+1, j}^{s+1} .
\end{aligned}
$$

Moreover, we follow Benabou (2002) and Brinca et al. (2016) and assume that labor income is taxed non-linearly so that our model is also able to capture the most important redistributive features of the tax system and its effects on inequality. The quarterly adjusted after-tax labor income $y_{t, j}^{s, n}$ is given by

$$
y_{t, j}^{s, n}=\frac{\theta_{0}}{4^{\theta_{1}}}\left(\frac{w_{t} e_{j}^{s} n_{t, j}^{s}}{1+\tilde{\tau}_{t}^{p}}\right)^{1-\theta_{1}}-\tau_{t}^{p}\left(\frac{w_{t} e_{j}^{s} n_{t, j}^{s}}{1+\tilde{\tau}_{t}^{p}}\right),
$$

where the scaling parameter $\theta_{0}$ controls the level of the tax code and $\theta_{1}$ its progressivity. Heathcote et al. (2016) provide empirical evidence that this functional form replicates the income distributions of pre-tax and after-tax incomes very well with an $R^{2}=0.91$. Furthermore, Brinca et al. (2016) show in their Appendix that the tax wedge between incomes does not depend on the parameter $\theta_{0}$. For this reason, a government can change the average tax rates by an adjustment of $\theta_{0}$ without affecting the progressivity in the tax system. The variables $\tau_{t}^{p}$ and $\tilde{\tau}_{t}^{p}$ are the tax rates

\footnotetext{
${ }^{18}$ In Appendix A.3.3, we conduct a sensitivity analysis with respect to a capital portfolio share that is hump-shaped over the life cycle.
} 
for social-security contributions paid by employees and by employers, respectively. For simplification, we set $\tilde{\tau}_{t}^{p}=\tau_{t}^{p}$ in the remainder of this paper.

Accordingly, the budget constraint of the $s$-year old Ricardian household with productivity type $j$ in period $t$ is given by:

$$
c_{t, j}^{s}+a_{t+1, j}^{s+1}=y_{t, j}^{s, n}+\left(q_{t}+\left(1-\tau_{t}^{k}\right) r_{t}\right) k_{t, j}^{s}+\frac{b_{t, j}^{s}}{\pi_{t}}+\text { pens }_{t, j} .
$$

The parameter $\tau_{t}^{k}$ denotes the capital income tax rate in period $t$. In addition to his labor and capital income, the household receives pensions $\operatorname{pen}_{t, j}^{s}$ which are only paid to retired agents at age $s>T_{w}$ and depend on the productivity type $j$. The public pay-as-you-go pension scheme will be described in more detail below. The first-order conditions corresponding to these households' problems are as follows:

$$
\begin{aligned}
\left(c_{t, j}^{s}\right)^{-\eta} & =\lambda_{t, j}^{s} \\
\gamma_{0}\left(n_{t, j}^{s}\right)^{\gamma} & =\lambda_{t, j}^{s}\left[\frac{\theta_{0}\left(1-\theta_{1}\right)}{4^{\theta_{1}}}\left(\frac{w_{t}^{f} e_{j}^{s} n_{t, j}^{s}}{1+\tau_{t}^{p}}\right)^{-\theta_{1}}-\tau_{t}^{p}\right]\left(\frac{w_{t}^{f} e_{j}^{s}}{1+\tau_{t}^{p}}\right), \\
\lambda_{t, j}^{s} & =\beta \phi_{s} E_{t}\left\{\lambda_{t+1, j}^{s+1} \frac{\left(q_{t+1}+\left(1-\tau_{t+1}^{k}\right) r_{t+1}\right)}{q_{t}}\right\}, \\
\lambda_{t, j}^{s} & =\beta \phi_{s} E_{t}\left\{\lambda_{t+1, j}^{s+1}\left(\frac{1+r_{t}^{b}}{\pi_{t+1}}\right)\right\}, \\
r_{t}^{i s} & =q_{t} \frac{\partial \delta\left(u_{t}\right)}{\partial u_{t}}
\end{aligned}
$$

with $r_{t}^{b} \equiv R_{t}^{b}-1$

\subsubsection{Rule-of-Thumb Consumers}

The $s$-year old rule-of-thumb consumers with productivity type $j \in\{1,2,3\}$ do not save. They maximize their instantaneous utility in every period $t$ :

$$
u\left(c_{t, j}^{s, R o T}, n_{t, j}^{s, R o T}\right)=\frac{\left(c_{t, j}^{s, R o T}\right)^{1-\eta}-1}{1-\eta}-\gamma_{0} \frac{\left(n_{t, j}^{s, R o T}\right)^{1+\gamma}}{1+\gamma}
$$


subject to the budget constraint

$$
c_{t, j}^{s, R o T}=\frac{\theta_{0}}{4^{\theta_{1}}}\left(\frac{w_{t} e_{j}^{s} n_{t, j}^{s, R o T}}{1+\tilde{\tau}_{t}^{p}}\right)^{1-\theta_{1}}-\tau_{t}^{p}\left(\frac{w_{t} e_{j}^{s} n_{t, j}^{s, R o T}}{1+\tilde{\tau}_{t}^{p}}\right)+p e n s_{t, j},
$$

where $c_{t, j}^{s, R o T}$ and $n_{t, j}^{s, R o T}$ denote consumption and labor supply of rule-of-thumb consumers, respectively. The first-order conditions with respect to $c_{t, j}^{s, R o T}$ and $n_{t, j}^{s, R o T}$ are

$$
\left(c_{t, j}^{s, R o T}\right)^{-\eta}=\lambda_{t, j}^{s}
$$

and

$$
\gamma_{0}\left(n_{t, j}^{s, R o T}\right)^{\gamma}=\lambda_{t, j}^{s}\left[\frac{\theta_{0}\left(1-\theta_{1}\right)}{4^{\theta_{1}}}\left(\frac{w_{t}^{f} e_{j}^{s} n_{t, j}^{s, R o T}}{1+\tau_{t}^{p}}\right)^{-\theta_{1}}-\tau_{t}^{p}\right]\left(\frac{w_{t}^{f} e_{j}^{s}}{1+\tau_{t}^{p}}\right)
$$

\subsection{Government Sector}

\subsubsection{Government Budget}

In the following sections, we aim to study the allocative, distributive, and welfare effects of a change in government consumption $G_{t}$. For this reason, we assume that government expenditures are exogenous and follow an $\mathrm{AR}(1)$ process:

$$
\ln \left(\frac{G_{t}}{G}\right)=\rho_{g} \ln \left(\frac{G_{t-1}}{G}\right)+\epsilon_{t}
$$

where $\epsilon_{t} \sim N\left(0, \sigma_{g}^{2}\right)$ and $G$ denotes the non-stochastic steady state value of government consumption. These expenditures are financed by deficits, $B_{t+1} /\left(R_{t}^{b}\right)-B_{t} / \pi_{t}$, confiscated accidental bequests $B e q_{t},{ }^{19}$ and tax revenues from capital income $\Psi_{t}^{k}$ and

\footnotetext{
${ }^{19}$ Our results are insensitive with regard to the assumption that accidental bequests are used as government revenues in the government budget constraint. Alternatively, we could have assumed perfect annuity markets. In this case, the resulting consumption-age profile would be increasing over the entire life-cycle as also demonstrated by Hansen and İmrohoroğlu (2008); this behavior, however, would be in contradiction to empirical findings of Fernández-Villaverde and Krueger (2007).
} 
labor income $\Psi_{t}^{n}$ which are given by

$$
\Psi_{t}^{k}=\tau_{t}^{k} r_{t} K_{t}
$$

and

$$
\begin{aligned}
\Psi_{t}^{n}= & \sum_{s=1}^{T_{w}} \sum_{j=1}^{3} \psi_{s} v_{j}\left(1-v_{R o T}\right)\left(1-\frac{\theta_{0}}{4^{\theta_{1}}}\left(\frac{w_{t} e_{j}^{s} n_{t, j}^{s}}{1+\tau_{t}^{p}}\right)^{-\theta_{1}}\right)\left(\frac{w_{t} e_{j}^{s} n_{t, j}^{s}}{1+\tau_{t}^{p}}\right)+ \\
& \sum_{s=1}^{T_{w}} \sum_{j=1}^{3} \psi_{s} v_{j} v_{R o T}\left(1-\frac{\theta_{0}}{4^{\theta_{1}}}\left(\frac{w_{t} e_{j}^{s} n_{t, j}^{s, R o T}}{1+\tau_{t}^{p}}\right)^{-\theta_{1}}\right)\left(\frac{w_{t} e_{j}^{s} n_{t, j}^{s, R o T}}{1+\tau_{t}^{p}}\right) .
\end{aligned}
$$

Thus, the government budget is presented by

$$
\frac{B_{t+1}}{R_{t}^{b}}=\frac{B_{t}}{\pi_{t}}+G_{t}-\Psi_{t}-B e q_{t}
$$

with $\Psi_{t}=\Psi_{t}^{k}+\Psi_{t}^{n}$. The average tax rate on labor income $\tau_{t}^{w}$ is expressed $\operatorname{as}^{20}$

$$
\tau_{t}^{w}=\frac{\Psi_{t}^{n}}{w_{t} N_{t}}+\frac{2 \tau_{t}^{p}}{1+\tau_{t}^{p}}
$$

The variable $N_{t}$ denotes aggregate efficient labor that will be defined below. We follow Galí et al. (2007) and assume that the government adjusts its tax revenues to a change in government spending and debt according to the fiscal rule:

$$
\frac{\left(\Psi_{t}-\Psi\right)}{Y}=\omega_{g} \frac{\left(G_{t}-G\right)}{Y}+\omega_{b} \frac{\left(B_{t} / \pi_{t}-B\right)}{Y},
$$

where $\omega_{G}$ and $\omega_{b}$ are positive constants that control the dynamics of tax revenues. In order to implement this fiscal rule, we assume that the government adjusts its tax revenues on labor and capital income, $\Psi_{t}^{n}$ and $\Psi_{t}^{k}$, and that, in accordance with empirical evidence for the US economy, the two income tax rates $\tau_{t}^{w}$ and $\tau_{t}^{k}$ are related by the following linear equation: ${ }^{21}$

$$
\tau_{t}^{k}=\beta_{0}^{k}+\beta_{1}^{k} \tau_{t}^{w}
$$

\footnotetext{
${ }^{20}$ Following Mendoza et al. (1994) and Trabandt and Uhlig (2011), this tax rate also comprises all social security contributions paid by employees and employers.

${ }^{21}$ In Appendix A.2, we graph the two tax rates for the US economy during 1985-2008. The correlation coefficient of these two tax rates amounts to 0.32 .
} 


\subsubsection{Social Security}

The social security authority collects contributions from workers to finance its pension payments to the retired agents. For simplification, we assume that pensions are constant over time. The individual pensions pen $_{t, j}$ for productivity types $j \in\{1,2,3\}$ are progressive and amount to ${ }^{22}$

$$
\begin{aligned}
\operatorname{pen}_{t, j}= & 0.9 \min \left(y_{j}, 0.22 \bar{y}\right)+0.32 \max \left(0, \min \left(y_{j}, 1.33 \bar{y}\right)-0.22 \bar{y}\right)+ \\
& 0.15 \max \left(0, \min \left(y_{j}, 2.90 \bar{y}\right)-1.33 \bar{y}\right),
\end{aligned}
$$

where $y_{j}$ describes the average gross labor market income over the 35 highest years of earnings and $\bar{y}$ denotes average earnings in the steady state of our model. ${ }^{23}$ In equilibrium, the budget of the social security authority is balanced:

$$
\sum_{j=1}^{3}\left(\sum_{s=T_{w}+1}^{T} \psi_{s} v_{j} \text { pen } n_{j}\right)=\left(\frac{2 \tau_{t}^{p}}{1+\tau_{t}^{p}}\right) w_{t} N_{t} .
$$

\subsection{Central Bank}

The monetary regime sets the nominal gross interest rate $R_{t}^{b}$ according to a simple Taylor rule:

$$
\ln \left(\frac{R_{t}^{b}}{R^{b}}\right)=\phi_{m} \ln \left(\frac{R_{t-1}^{b}}{R^{b}}\right)+\left(1-\phi_{m}\right) \phi_{\pi} \ln \left(\frac{\pi_{t}}{\pi}\right),
$$

where $\phi_{m}$ controls the degree of interest rate smoothing and $\phi_{\pi}>1$ represents the response coefficient for inflation. The variables $R^{b}$ and $\pi$ denote the nominal gross interest rate and the inflation factor in the non-stochastic steady state.

\footnotetext{
${ }^{22}$ See also page 202 in OECD (2007) which provides a detailed description of the pension benefit formula and the corresponding thresholds of average earnings for the US.

${ }^{23}$ For simplification, we assume that pensions do not depend on past contributions.
} 


\subsection{Equilibrium Conditions}

In equilibrium, aggregate variables are equal to the sum of the individual variables:

$$
\begin{aligned}
K_{t+1}= & \sum_{s=2}^{T} \sum_{j=1}^{3}\left(1-v_{R o T}\right) \psi_{s-1} v_{j} k_{t+1, j}^{s} \\
I_{t}= & \sum_{s=2}^{T} \sum_{j=1}^{3}\left(1-v_{R o T}\right) v_{j}\left[\psi_{s} k_{t+1, j}^{s+1}-\left(1-\delta\left(u_{t}\right)\right) \psi_{s-1} v_{j} k_{t, j}^{s}\right] \\
B_{t}= & \sum_{s=2}^{T} \sum_{j=1}^{3}\left(1-v_{R o T}\right) \psi_{s-1} v_{j} b_{t, j}^{s}, \\
N_{t}= & \sum_{s=1}^{T} \sum_{j=1}^{3} \psi_{s} v_{j} e_{j}^{s}\left[\left(1-v_{R o T}\right) n_{t, j}^{s}+v_{R o T} n_{t, j}^{s, R o T}\right] \\
C_{t}= & \sum_{s=1}^{T} \sum_{j=1}^{3} \psi_{s} v_{j}\left[\left(1-v_{R o T}\right) c_{t, j}^{s}+v_{R o T} c_{t, j}^{s, R o T}\right] \\
B e q_{t+1}= & \sum_{s=2}^{T} \sum_{j=1}^{3}\left(1-v_{R o T}\right) \psi_{s-1} v_{j}\left(1-\phi_{s-1}\right)\left[\frac{b_{t+1, j}^{s}}{\pi_{t+1}}+\right. \\
& \left.+\left(\left(1-\tau_{t+1}^{k}\right) r_{t+1}+q_{t+1}\right) k_{t+1, j}^{s}\right] .
\end{aligned}
$$

Profits in the capital producer sector are equal to zero, $\Omega_{t}^{c}=0$, and the aggregate resource constraint is given by:

$$
Y_{t}=I_{t}^{d}+C_{t}+G_{t}
$$

\section{Calibration}

Since we are interested in the short run effects of an unanticipated government spending shock, we calibrate the model on a quarterly basis and linearize the model around a steady state with zero inflation. ${ }^{24}$ Most of our parameters are standard in the RBC/DSGE literature and are summarized in Table 1.

\footnotetext{
${ }^{24}$ We use the perturbation methods described in Chapters 9 and 10 in Heer and Maußner (2009).

For the generalized Schur decomposition, we use code provided by Giordani and Söderlind (2004).
} 


\section{Production}

\begin{tabular}{|c|c|c|c|}
\hline Capital Share: & $\alpha=0.36$ & Utilization Rate: & $u=1$ \\
\hline Depreciation Rate: & $\delta=0.025$ & Depreciation Elasticity: & $\epsilon_{u}=1$ \\
\hline Price Elasticity (GS): & $\epsilon=6$ & Price of Capital: & $q=1$ \\
\hline Price Stickiness (GS): & $\phi=0.75$ & Price Elasticity (CS) : & $\zeta=1$ \\
\hline \multicolumn{4}{|c|}{ Demographics } \\
\hline Maximum Age: & $T=240$ & Periods as Retiree: & $T_{r}=80$ \\
\hline Periods as Worker: & $T_{w}=160$ & Share of RoT-Consumers: & $\nu_{R o T}=0.43$ \\
\hline s.d. of individual productivity: & $\sigma_{z}=\sqrt{3.60}$ & & \\
\hline \multicolumn{4}{|c|}{ Government } \\
\hline Spending Share: & $G / Y=0.2$ & Parameter (Fiscal Rule): & $\omega_{g}=0.10$ \\
\hline Parameter (AR(1)-Process): & $\rho_{g}=0.87$ & Parameter (Fiscal Rule): & $\omega_{b}=0.33$ \\
\hline s.d. (AR(1)-Process): & $\sigma_{g}=0.016$ & Parameter (Capital Tax): & $\beta_{0}^{k}=0.2$ \\
\hline Parameter (Labor Income Tax): & $\theta_{0}=0.88$ & Parameter (Capital Tax): & $\beta_{1}^{k}=0.58$ \\
\hline Parameter (Labor Income Tax): & $\theta_{1}=0.137$ & Government Debt to GDP: & $B / Y=1.71$ \\
\hline PAYG: See equation (36) & & & \\
\hline \multicolumn{4}{|c|}{ Central Bank } \\
\hline Inflation: & $\pi=1$ & Parameter (Taylor Rule): & $\phi_{m}=0.90$ \\
\hline Parameter (Taylor Rule): & $\phi_{\pi}=1.1$ & & \\
\hline
\end{tabular}

Table 1: Quarterly Parameterization of the OLG model.

Production. With regard to the production technology, we pick a standard value of $\alpha=0.36$ for the production elasticity of capital. We set the utilization rate $u$ equal to 1 in the steady state of our model and determine the parameters $\delta_{0}$ and $\delta_{1}$ such that the depreciation rate $\delta$ is equal to 0.025 . The parameter $\zeta$ from the capital adjustment cost function (11) is set to 1 following Galí et al. (2007). ${ }^{25}$ We choose a standard value for the price elasticity equal to $\epsilon=6$ implying a gross price markup of 1.2 in the steady state, where the degree of price stickiness $\varphi$ is set to

\footnotetext{
${ }^{25}$ In Appendix A.3.1, we report results for the cases $\zeta=0$, where adjustment costs of capital play no role in the transmission of fiscal policy, and $\zeta=4$.
} 
0.75. Moreover, we assume that aggregate profits are equal to zero in the steady state in order to calibrate the fixed $\operatorname{costs} F$. Our calibration of the elasticity $\epsilon_{u}$ of the change in the depreciation rate with respect to the utilization rate follows Baxter and Farr (2005) who pick a value of 1 that is also supported by empirical estimates in Basu and Kimball (1997). Finally, we follow Uhlig (2007) and set the parameter $\mu$ governing the real wage rigidity in equation (8) equal to 0.8 .

Demographics and Individual Productivity. A household lives $T=240$ quarters and supplies labor in the first $T_{w}=160$ quarters. Moreover, the age-specific survival probabilities $\psi_{s}$ stem from Arias (2014) and describe the year 2010. The idiosyncratic productivity level is given by $e_{j}^{s}=z_{j} \bar{e}_{s}$. The age-specific component $\bar{e}_{s}$ denotes the average efficiency at age $s$ which is taken from Hansen (1993) and interpolated to in-between quarters. As a consequence, the model replicates the cross-section age distribution of earnings of the U.S. economy. With regard to the idiosyncratic component $z_{j}$, we follow Huggett (1996) and choose a log-normal distribution of earnings for the youngest households with a variance equal to $\sigma_{z}^{2}=3.60$. This variance is chosen so that the Gini coefficients of labor income, gross market income, and wealth are close to the empirical values reported by Budría Rodríguez et al. (2002) that we describe in the next section.

We set the share of rule-of-thumb consumers $v_{R o T}$ equal to $43 \%$ which is in line with the estimates found in the literature. For example, Campbell and Mankiw (1989, 1991) provide empirical evidence that this parameter ranges between $35 \%$ and $50 \%$ in the United States. Furthermore, Shapiro and Slemrod (1995) find in a survey that $43 \%$ of consumers planned to spend most of the increase in disposable income with respect to the 1992 change in the standard income tax withholding amounts. ${ }^{26}$

Households. With respect to the preference parameters, we set the discount factor $\beta=1.006$ in order to match a risk-free interest rate on government bonds of $r^{b}=$ $4.0 \%$. The elasticity of marginal utility with respect to consumption is equal to $\eta=2$ and the parameter $\gamma_{0}$ is calibrated so that the average labor supply is equal

\footnotetext{
${ }^{26}$ In Appendix A.3.2, we conduct a sensitivity analysis for the cases $v_{R o T}=0.35$ and $v_{R o T}=0.50$.
} 
to $33 \%$ of available time. The Frisch elasticity of labor supply is given by $1 / \gamma$. For example, MaCurdy (1981) and Altonij (1986) both use PSID data in order to estimate values of 0.23 and 0.28 , respectively, while Killingsworth (1983) finds an US labor supply elasticity equal to 0.4 . We will use the conservative estimate $1 / \gamma=0.2$ in accordance with Galí et al. (2007).

Government. The share of government spending in GDP is set to $G / Y=20 \%$. The term $\rho_{g}$ regarding the first-order autoregressive process of government spending is equal to 0.87 and the standard deviation of innovations to government consumption amounts to $\sigma_{g}=0.016$ as in Schmitt-Grohé and Uribe (2007). In accordance with Brinca et al. (2016), we set the ratio of government debt to quarterly GDP equal to $B / Y=0.428 \times 4$, the parameter $\theta_{0}=0.888$ and the tax progressivity $\theta_{1}=0.137$. For this reason, we scale all productivity profiles by a constant so that the government's budget is balanced and a regression of net labor incomes on gross labor incomes yields both of the aforementioned values in the steady state of our model. Moreover, we use a data-set provided by Gomme et al. (2011) in order to estimate the income tax parameters $\beta_{0}^{k}=0.20$ and $\beta_{1}^{k}=0.58$ using the observations from the period 1985-2008. The corresponding average tax rates for labor and capital income in the steady state amount to 0.25 and 0.34 , respectively, which are also in good accordance with the reported values by Brinca et al. (2016) and Trabandt and Uhlig (2011). With regard to the calibration of the dynamics of tax revenues and debt, we use parameter values provided by Galí et al. (2007) who estimate an elasticity of tax revenues with respect to government spending of $\omega_{g}=0.1$ that is close to the estimate in Blanchard and Perotti (2002). We also follow these authors and set the elasticity of taxes with respect to debt equal to $\omega_{b}=0.33$. The parameters for the pension benefit formula are given in equation (36). In the steady state, the replacement ratio of pensions relative to average gross wage earnings is equal to 0.37. Finally, the interest rate rule of the central bank satisfies the Taylor principle and we set the parameters $\phi_{m}$ and $\phi_{\pi}$ equal to 0.9 and 1.1 following Walsh (2005). 


\section{Steady State Behavior}

In this section, we first describe the life-cycle behavior of Ricardian and rule-ofthumb households in steady state. Then we present the corresponding inequality measures of income and wealth and discuss how well our model replicates the data for the US.

\subsection{Life-Cycle Profiles of Ricardian Households and Rule- of-Thumb Consumers}

Fig. 1 presents the steady-state behavior of Ricardian households and rule-of-thumb consumers over the life-cycle with respect to the productivity types $j \in\{1,2,3\}$. The profiles of consumption as displayed in the upper panels are hump-shaped. The consumption of Ricardians declines only in retirement after age 68 and accords with empirical observations in its qualitative features. ${ }^{27}$ For the US economy, Fernández-Villaverde and Krueger (2007) find that the empirical consumption-age profiles display a significant hump over the life cycle even after correcting for the change of the family size. For the high-education households (that are roughly corresponding to the high-productivity households in our model), the peak occurs at age 55, while the low-education households attain their consumption maximum at an earlier age close to 50 and the hump is much smaller. Therefore, in our model, the hump in consumption of the Ricardian households occurs somewhat too late in the life cycle. However, the consumption of rule-of-thumb consumers in the upper right panel drops earlier in life at age 51 so that total consumption of the different productivity types peaks much earlier in life in accordance with the aforementioned empirical evidence.

The profile of working hours of Ricardian households is depicted in the left panel of the second row. Their labor supply stays almost constant during the first 10

\footnotetext{
${ }^{27}$ For the reader's convenience, we use the real life age in years rather than the quarterly age index $s$ in the figures hereinafter.
} 
Consumption (Ric)
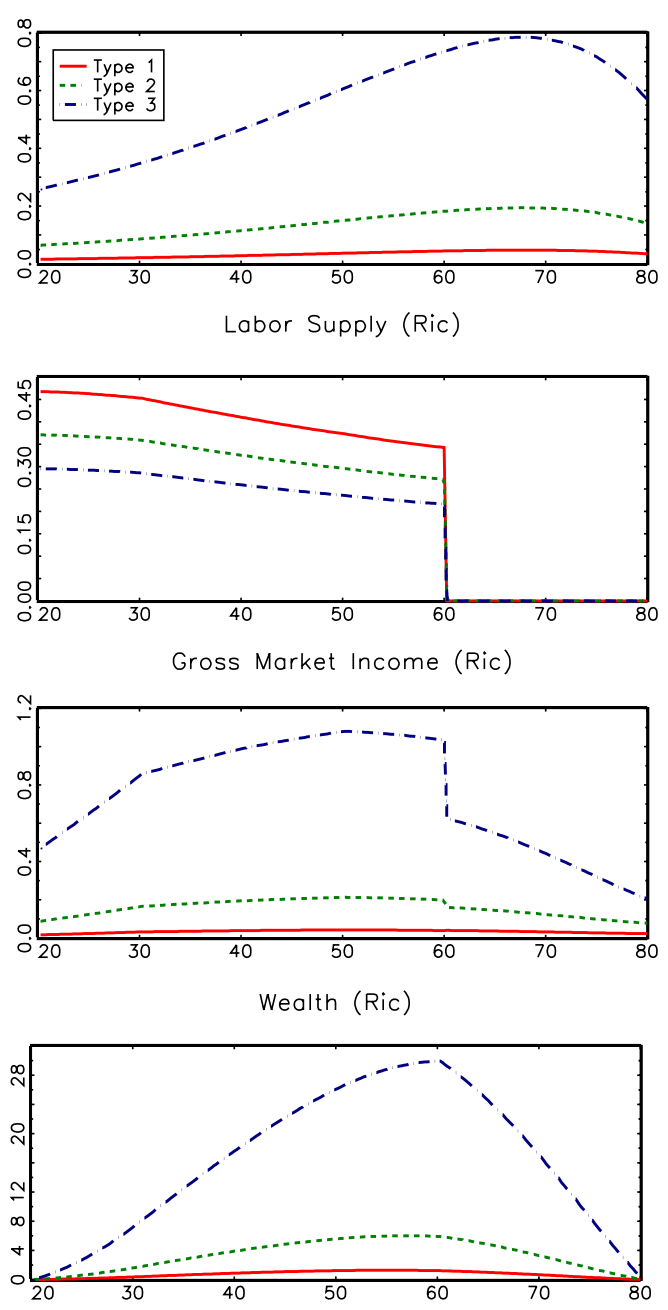

Consumption (RoT)
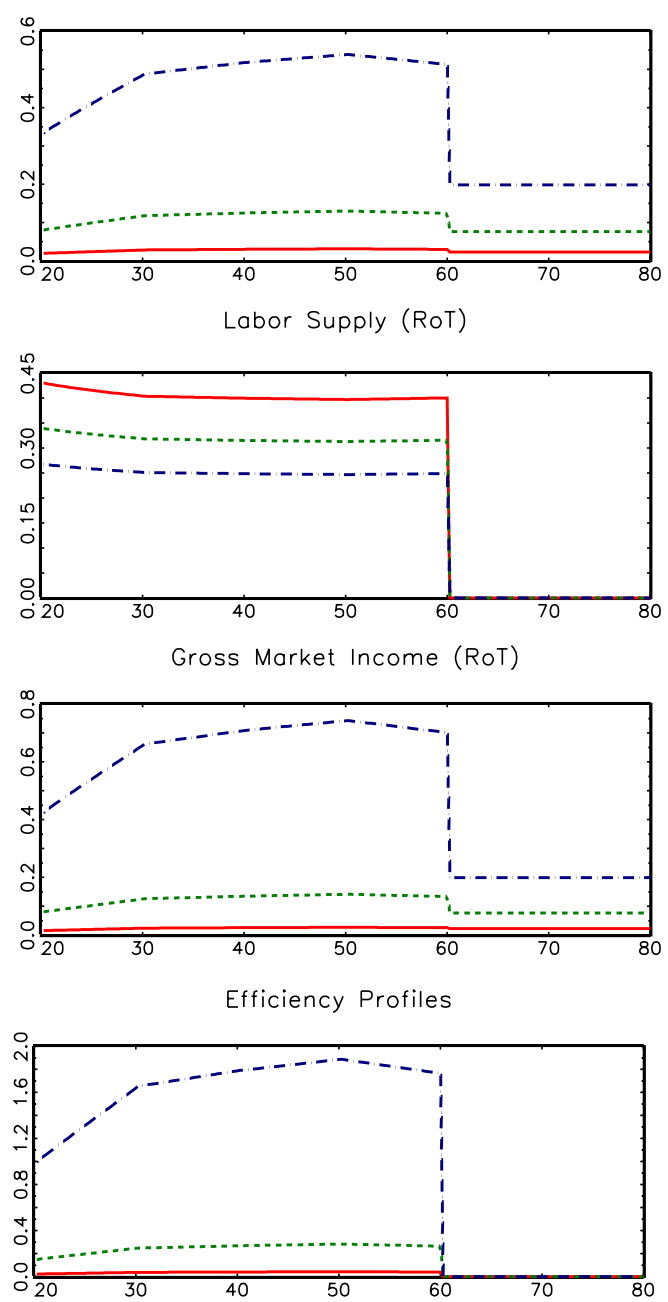

Figure 1: Steady-State Behavior of Ricardians (Ric) and Rule-of-Thumb Consumers (RoT). Abscissa: Age in years. Types 1 to 3: Productivity types $j \in\{1,2,3\}$.

years and falls monotonously thereafter. This pattern is mainly driven by both the increasing wealth effect as agents build up savings for retirement and the humpshaped efficiency profile over the life cycle that is displayed in the lower right panel. In contrast, the labor supply of rule-of-thumb consumers does not fall substantially during working life because the wealth effect is absent. The panels in the third row display the gross market incomes of Ricardian households and rule-of-thumb consumers. These profiles follow a hump-shaped pattern and feature a kink after households enter retirement due to the absence of labor income. Moreover, this kink 
is more pronounced for rule-of-thumb consumers since Ricardian households receive an income stream from their savings during retirement. Finally, since pensions are below the wage income, all Ricardian households save for retirement and accumulate wealth until the last period of their working life as presented in the lower left panel, where the share of riskless assets in their portfolios amounts to $\chi=22$ percent.

\subsection{Inequality}

The heterogeneity with regard to individual productivity, $z_{j} \bar{e}_{s}$, and consumption type (Ricardian versus rule-of-thumb consumer) results in inequality of income and wealth among the households. The Gini coefficients of income, wealth, and consumption amount to 0.573 (gross income before taxes), 0.625 (gross labor income), 0.789 (wealth), and 0.531 (consumption). Our inequality measures for incomes and wealth are very close to the empirical values. For example, Budría Rodríguez et al. (2002) report Gini coefficients of (gross) income, (gross) labor income and wealth that are equal to $0.553,0.661$ and 0.803 , respectively. Table 2 reports the shares of total wealth and gross market income held by quintile groups. The distributions of both variables are highly unequal with the top quintiles holding $83.3 \%$ and $60.1 \%$ of aggregate wealth and gross market income, respectively. Furthermore, all wealth and income shares are also almost in line with the empirical evidence presented by Budría Rodríguez et al. (2002) as shown in the third and sixth row in Table $2 .^{28}$

\footnotetext{
${ }^{28}$ Our model, however, falls short to replicate the high income and wealth shares in the top $1 \%$ to $10 \%$ percentiles for two reasons: 1) We do not consider self-employed workers and entrepreneurs. Quadrini (2000) presents empirical evidence that the concentration of income and wealth is higher among entrepreneurs and that the introduction of an endogenous entrepreneurial choice in a dynamic general equilibrium model helps to reconcile the inequality in the model with that of the US economy. In related research, Cagetti and de Nardi (2009) introduce endogenous entrepreneurship in an OLG model. 2) We omit bequests. Among others, De Nardi and Yang (2016) set up a model that considers both bequests of wealth and inheritance of abilities from the parents and is able to match the skewness of the distribution of income, wealth, and bequests. See De Nardi (2015) for a survey of modeling wealth heterogeneity in quantitative general equilibrium models.
} 
Krueger et al. (2010) document the evolution of income and wealth heterogeneity over time and notice that the inequality of earnings has increased in many countries, including the US, over the last three decades. Our model, however, overestimates the Gini coefficient for consumption which is equal to 0.29 for the year 2003 according to Krueger and Perri (2006) since households do not face idiosyncratic income risk in our model. ${ }^{29}$

\begin{tabular}{l|l|l|l|l|l}
\multicolumn{7}{c}{ Wealth } \\
\hline Quintiles: & Q1 & Q2 & Q3 & Q4 & Q5 \\
\hline Share (Model): & 0.000 & 0.000 & 0.023 & 0.144 & 0.833 \\
\hline Share (Data*): & -0.003 & 0.013 & 0.050 & 0.122 & 0.813 \\
\hline
\end{tabular}

Gross Market Income

\begin{tabular}{l|l|l|l|l|l}
\hline Quintiles: & Q1 & Q2 & Q3 & Q4 & Q5 \\
\hline Share (Model): & 0.017 & 0.044 & 0.100 & 0.237 & 0.601 \\
\hline Share (Data*): & 0.024 & 0.072 & 0.125 & 0.200 & 0.580 \\
\hline
\end{tabular}

Table 2: Shares of Total Wealth and Income by Quintiles. *See Budría Rodríguez et al. (2002), Table 6 and 7.

\section{The Effects of a Government Spending Shock and Public Financing}

In this section, we present our main results on the effects of an unanticipated increase of government consumption. We assume, in particular, that the parameter $\phi_{0}$ adjusts such that the government budget is always balanced, while the progressivity (defined by the tax wedges) in the tax system remains unaffected. First, we present the responses of aggregate variables and show that, in accordance with the empirical

\footnotetext{
${ }^{29}$ For example, Iacoviello and Pavan (2013) show that a model with overlapping generations and heterogeneous agents facing idiosyncratic and aggregate risks can explain this lower value.
} 
and theoretical results of Galí et al. (2007), output, consumption, employment, and real wages increase, while investment declines. Second, we illustrate the responses of individual consumption, labor, income and wealth and study the corresponding effects on inequality. The change in inequality is quantitatively stronger if extra government expenditures are financed by debt rather than taxes. Third, we study welfare effects of government consumption shocks on ex-post lifetime utility and are able to distinguish households who favor tax financing from those who favor debt financing.

\subsection{Aggregate Variables}

Fig. 2 displays the impulse responses of aggregate variables to an increase of government consumption $G_{t}$ by one standard deviation. In particular, we set the relative weights of government expenditures and debt to $\omega_{g}=0.1$ and $\omega_{b}=0.33$ in our fiscal rule (34) that describes the reaction function of tax revenues. We will refer to this case as "debt financing" which is illustrated in the upper panels of Fig. 2. In the bottom part of the figure, we compare it to the case of "tax financing", where we increase the reaction coefficient of taxes with respect to government expenditures $\omega_{g}$ from 0.1 to 0.9 .

A debt-financed increase of government consumption in our New Keynesian model has the well-known effects on aggregate variables. Prices are sticky and when government demand increases, monopolistic firms increase production. As a consequence, output increases by $0.39 \%$ (see upper left panel in Fig. 2) when government spending increases by one standard deviation, or, put differently, 0.32 percent of steady state output (see lower right panel) ${ }^{30}$. Hence, the spending multiplier amounts to 1.22 in period 2 in good accordance with empirical evidence provided by Blanchard and

\footnotetext{
${ }^{30}$ In our economy, we assume that markets are complete so that households are not subject to a borrowing constraint. Therefore, our model is implying a lower fiscal multiplier than the corresponding incomplete-market economy. In this vein, Brinca et al. (2016) have shown that the presence of borrowing constraints increases the fiscal multiplier. In particular, they find that their benchmark fiscal multiplier increases from 0.11 to 0.29 when the number of credit-
} 
Debt Financing:
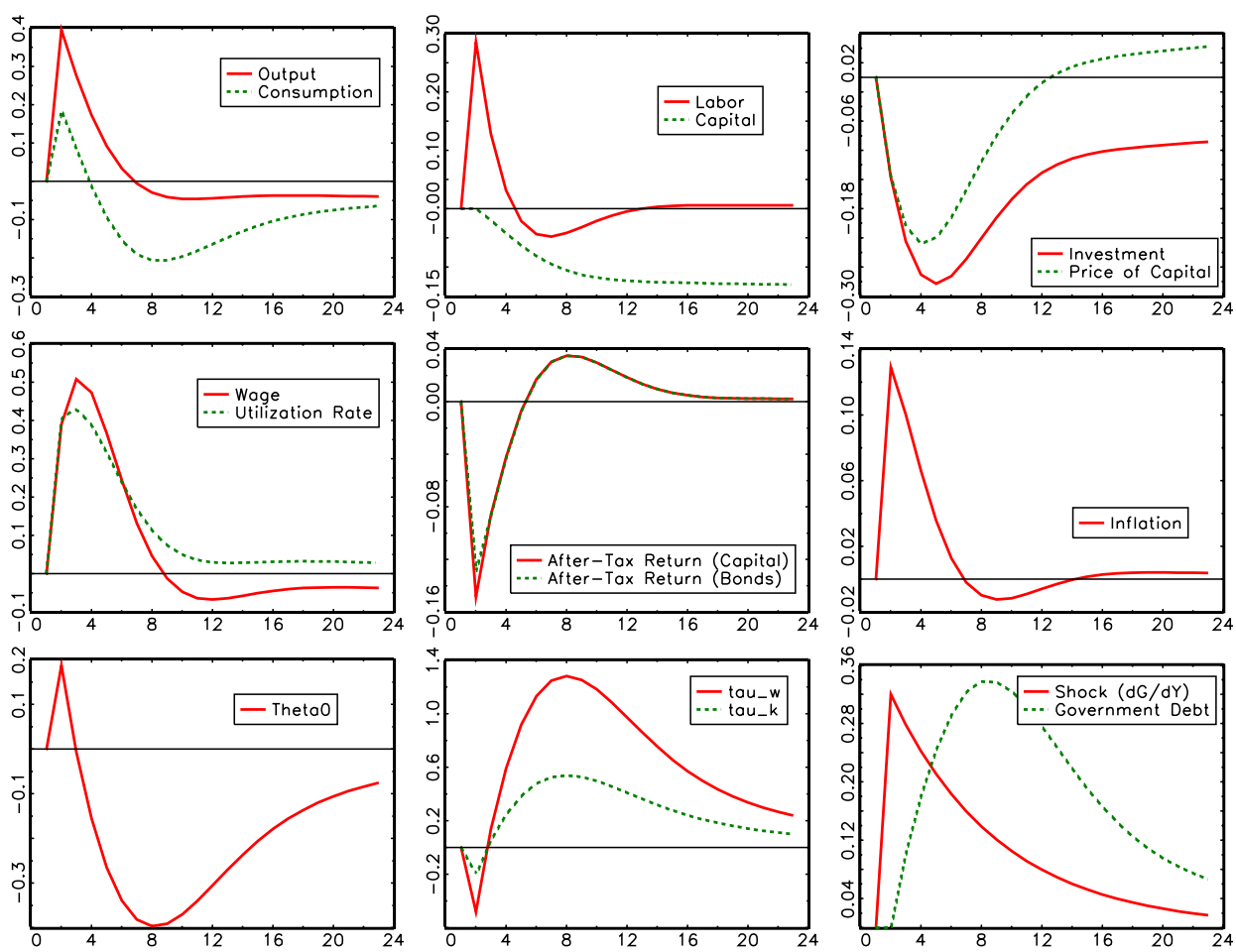

Tax Financing:
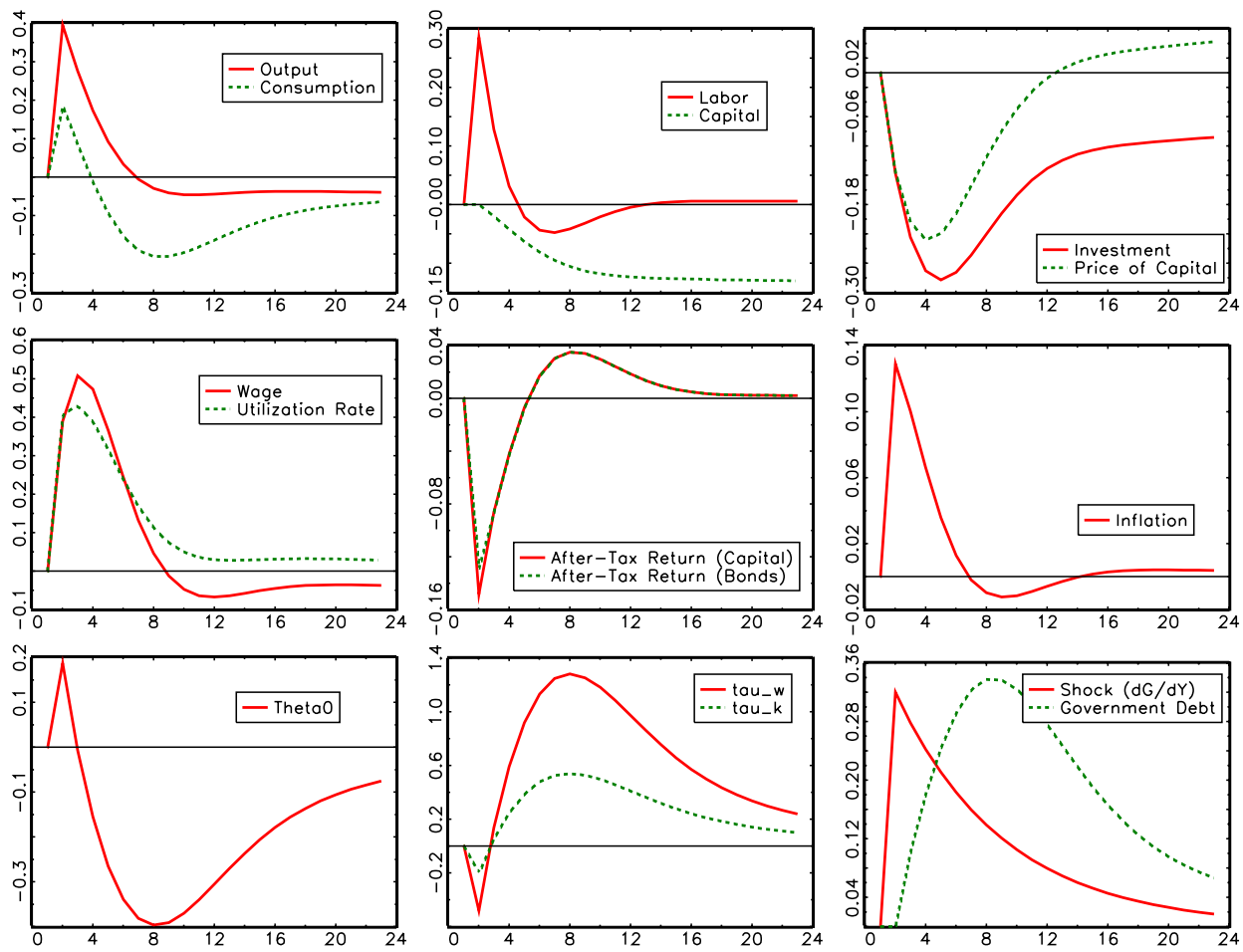

Figure 2: Impulse responses of aggregate variables under debt and tax financing (Shock: log-deviation of Government Spending in percent deviations from steady state output, Other variables: log-deviation in percent deviations from its steady state values). Abscissa: Periods after shock in $t=2$. 
Perotti (2002). ${ }^{31}$ In addition, government consumption crowds out capital since the government issues more bonds $B_{t}$ while investment $I_{t}$ declines. As a consequence, the price of capital $q_{t}$ falls from $-0.14 \%$ in period 2 to $-0.21 \%$ in period 4 and increases in the subsequent periods (see upper right panel). The aggregate labor supply rises by $0.29 \%$ (see middle panel in the upper row) because future tax increases constitute a negative wealth effect. In our model, this wealth effect is reinforced for Ricardian households with positive wealth because the price of capital $q_{t}$ and the (after tax) returns on both assets, capital and bonds, decline. Since prices are sticky and adjust only slowly, the mark-up falls and outweighs the effect of a lower marginal product of labor so that real wages (see left panel in the second row) increase in accordance with empirical evidence. ${ }^{32}$ While Ricardian households decrease consumption, ruleof-thumb consumers increase consumption so that aggregate private consumption increases. Moreover, the higher demand induces an increase in inflation and raises the utilization rate of capital. Government debt increases to $0.34 \%$ until period 9 and declines afterwards as depicted in the right panel in the third row of Fig. 2. Taxes on labor and capital income decrease in the first periods due to the increases in labor supply and wages. However, the increase in government debt $B_{t}$ subsequently reverses the initial negative impulse responses.

constrained households increases from $10 \%$ to $50 \%$. The reason is straightforward. Creditconstrained households have to decrease consumption to a larger extent than unconstrained households ceteris paribus. In order to circumvent the large drop in consumption, households have to increase their labor supply so that aggregate production even increases. The introduction of credit constraints into our model would also be likely to increase the fiscal multiplier, but to a smaller extent than in Brinca et al. (2016). In our model, a large fraction of the worker behaves as rule-of-thumb consumers who do not accumulate any savings and are characterized by constant (zero) wealth. Therefore, these households would not be affected by the presence of incomplete markets in the form of a borrowing constraint.

${ }^{31}$ Blanchard and Perotti (2002) report that empirical estimates of government multipliers are typically close to one for the US economy.

${ }^{32}$ If we did not consider rule-of-thumb consumers, but only Ricardian households, real wages would fall because the labor supply response is stronger among the latter due of the wealth effect. 
As discussed in the Introduction, the empirical response of real interest rates to an unexpected increase in government consumption is ambiguous, while more recent evidence points to a negative effect. In our model, real interest rates decline as illustrated in the panel in the second row and second column in Fig. 2. Standard New-Keynesian and neoclassical models, however, imply that real interest rates increase in response to an unexpected increase in government consumption. In Keynesian models, aggregate demand rises so that interest rates have to increase to induce households and firms to delay consumption and/or investment. In neoclassical models, higher government demand decreases household wealth so that households increase their labor supply subsequently. In accordance with these standard models, aggregate demand and labor supply also increase in our model, while investment falls. In contrast, however, we assume that the price of capital (in units of the final good) and the utilization rate of capital are flexible. As the price of capital falls in response to higher government demand, the utilization rate of capital increases. For these reasons the total real return on capital falls after a government spending shock according to equations (16) and (18). Moreover, the real return on bonds also follows this pattern due to the no-arbitrage condition given by equation (24c) and $(24 \mathrm{~d}) \cdot{ }^{33}$

The lower panels in Fig. 2 illustrate the impulse responses for the case of higher tax financing. In this case, the qualitative responses are almost the same, but differ in size. As can be seen in the lower middle panel, labor income taxes $\tau_{t}^{w}$ (that are the sum of a payroll tax $\tau_{t}^{g}$ and social security contributions $\tau_{t}^{p}$ ) increase on impact (by $1.11 \%$ ) since the government shifts the tax burden in the present. As a consequence, aggregate labor supply increases less and, hence, the output response is also smaller and only amounts to $0.28 \%$ in period 2 . Since the net market income of households is also lower due to higher taxes, aggregate private consumption decreases by $0.02 \%$

\footnotetext{
${ }^{33}$ Murphy and Walsh (2016) emphasize a different mechanism how higher government spending may lead to lower real interest rates. In their model, rising incomes increase the supply of loans and relaxes credit markets.
} 
in $t=2 .{ }^{34}$ The decline in the price of capital is also less pronounced. In particular, the price of capital $q_{t}$ drops from $-0.11 \%$ in period 2 to $-0.20 \%$ in period 5 and increases in the subsequent periods.

\subsection{Income and Wealth Inequality}

Fig. 3 presents the impulse responses of the Gini coefficient of gross market income, wealth, gross labor income and consumption in response to a one standard deviation increase in government spending over time. The solid (shaded) lines depict the case of tax financing (debt financing). On impact, the Gini coefficient of gross market income decreases by $0.022 \%$ until period 4 and increases in the subsequent periods under debt financing. Furthermore, the decline in the prices of capital $q_{t}$ reduces the wealth of Ricardian consumers so that wealth heterogeneity also falls. However, the effects of an increase in government spending on wealth inequality are rather negligible. The maximum impact occurs in period $t=6$, when the Gini coefficient of wealth decreases by approximately $0.011 \%$. In contrast, the Gini coefficient of gross labor income rises slightly to $0.006 \%$ in period 2 and decreases in the subsequent periods. Thus, the aforementioned decline of the Gini coefficient of gross market income is mainly driven by decreasing asset returns. Moreover, consumption inequality also decreases since the consumption of rule-of-thumb consumers increases, whereas Ricardian Household expect higher financial burdens in the future and, therefore, decrease their consumption. ${ }^{35}$ Under tax financing, the Gini coefficients follow very similar patterns which, however, are less pronounced for wealth, gross labor income, and consumption.

Remember though that the Gini coefficient is an aggregate measure. The redistribution that takes place on the disaggregate level is nevertheless quantitatively

\footnotetext{
${ }^{34}$ The result is in accordance with the findings of Galí et al. (2007) who also finds a negative effect for this parameter value of $\omega_{g}$ in their Fig. 7 .

${ }^{35}$ Anderson et al. (2016) and De Giorgi and Gambetti (2012) provide empirical evidence that government spending shocks decrease consumption inequality.
} 
Gini - Gross Market Inc.
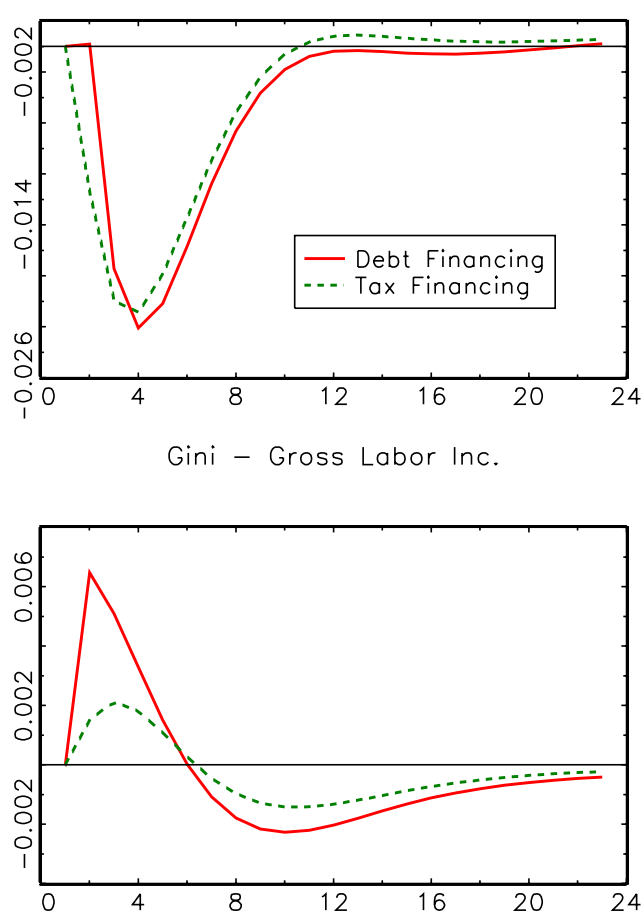

Gini - Wealth
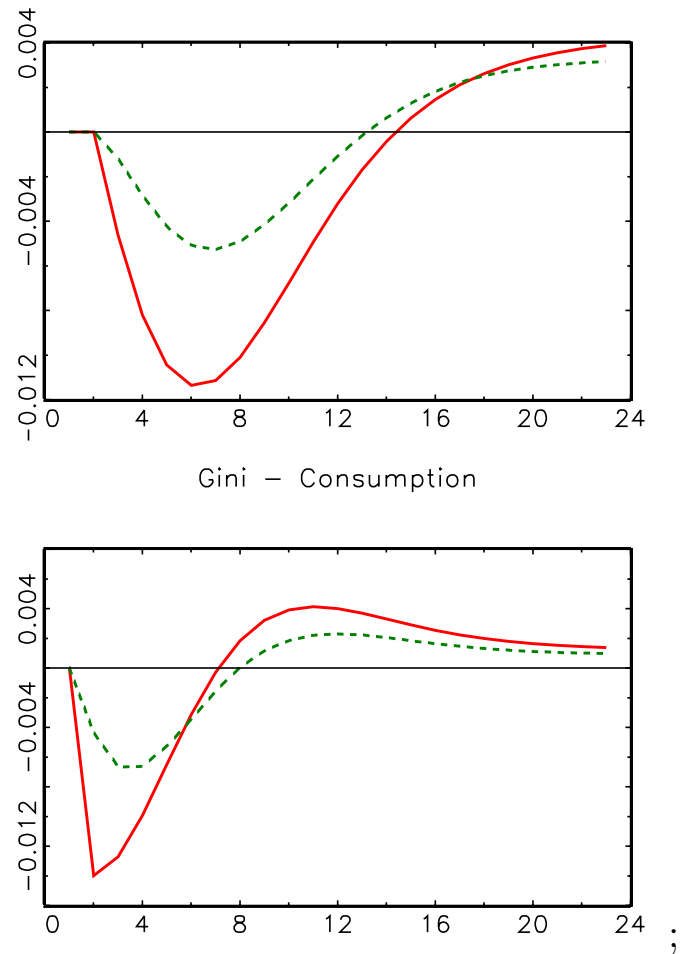

Figure 3: Impulse responses of Gini Coefficients (percent deviations) - Abscissa: Periods after shock in $t=2$.

significant even though the responses of the Gini coefficients are very small. Fig. 4 displays the the behavior of Ricardian households and rule-of-thumb consumers with respect to the financing form in the impact period $t=2$ when the shock occurs. Variables are expressed as absolute deviations from their steady-state value and are scaled by a factor of $100 .{ }^{36}$

In the case of debt financing (first three rows), the gross market income of highproductivity Ricardian (RoT) households increases by $0.39 \%(0.22 \%)$ for the 20 year-old workers in period $t=2$, while it declines by $0.52 \%$ for the retired 61 -year old Ricardian households due to decreasing asset returns which can not be compensated by an increase in labor supply. In particular, we observe that there is considerable redistribution among Ricardian households with similar gross incomes. Some of

\footnotetext{
${ }^{36}$ If we had used percentage deviations instead, individuals with age-specific wealth close to zero would have displayed very large impulse responses.
} 


\section{Debt Financing:}

Gross Market Income (Ric)

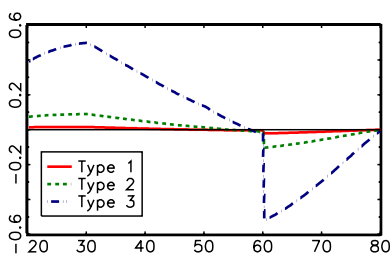

Gross Market Income (RoT)

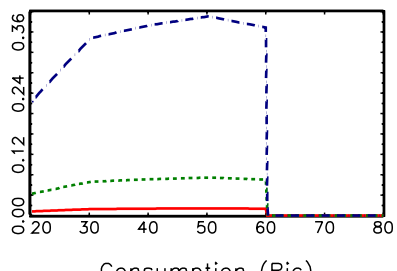

Consumption (Ric)

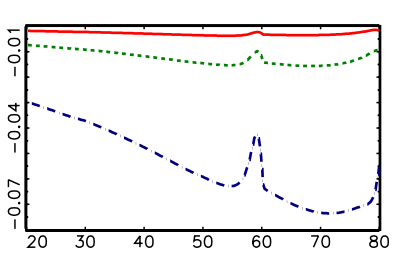

Tax Financing:

Gross Market Income (Ric)

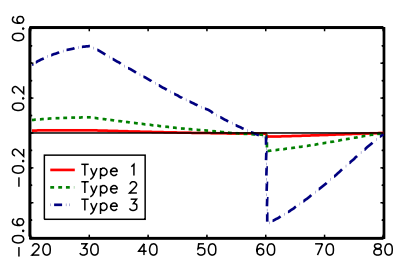

Gross Market Income (RoT)
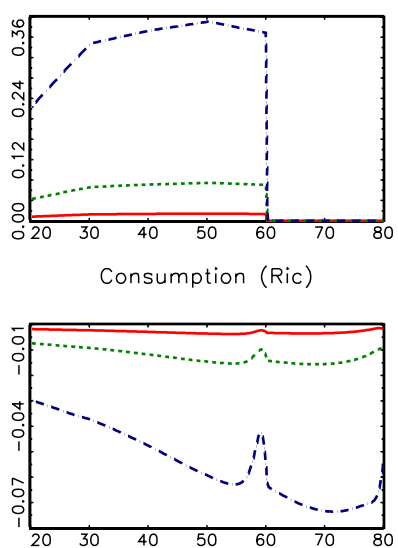

Gross Labor Income (Ric)

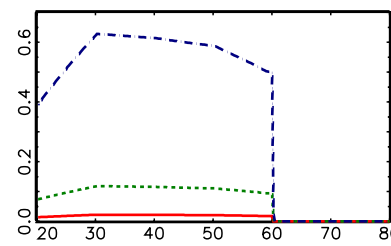

Gross Labor Income (RoT)

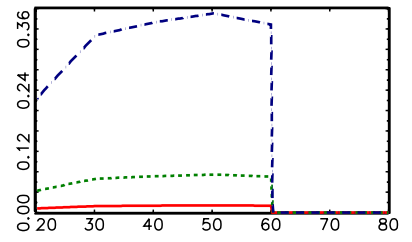

Consumption (RoT)

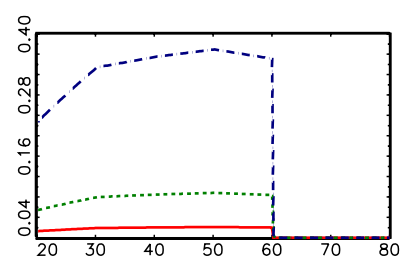

Gross Labor Income (Ric)

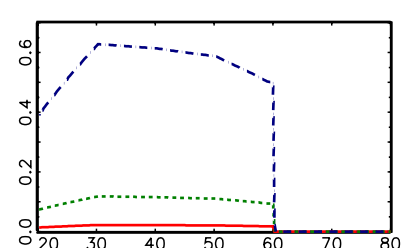

Gross Labor Income (RoT)
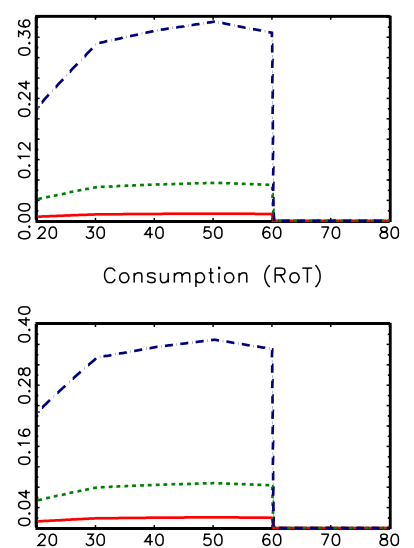

Labor Supply (Ric)

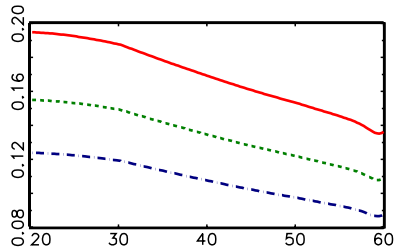

Labor Supply (RoT)
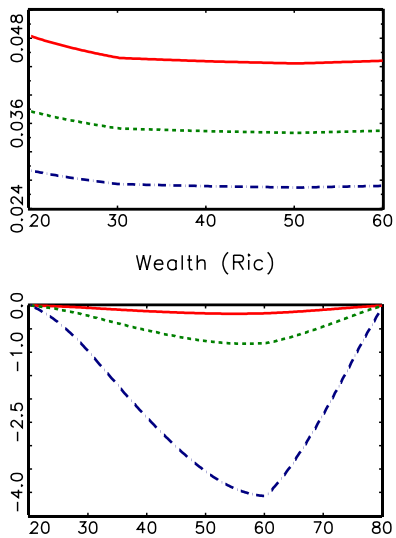

Labor Supply (Ric)

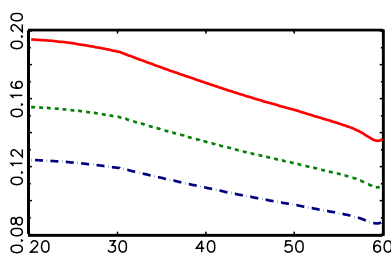

Labor Supply (RoT)
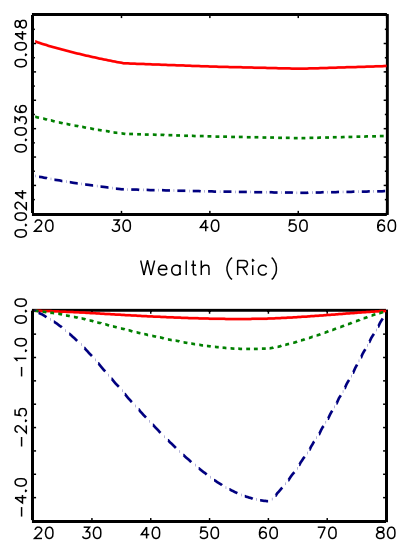

Figure 4: Cross-Section - Ricardian Households (Ric) \& Rule-of-Thumb Consumers (RoT) in $t=2$ (a.d. \& s.f.=100). Abscissa: Age in years. Types 1 to 3: Productivity types $j \in\{1,2,3\}$. 
the income-poor households increase their gross income, e.g. the low-productivity households at young age, while other income-poor households experience a decline in their gross income, e.g. the retired Ricardian households in old age. Similarly, there is considerable redistribution among medium-income and high-income households as young workers with productivity $j \in\{2,3\}$ increase their income, while Ricardian retired households with high wealth receive smaller incomes. On the aggregate level, these various changes almost cancel.

As a consequence of the higher wage and the increase in labor supply across all workers (see the two upper right panels), the gross labor incomes of both rule-of-thumb consumers and Ricardian households increase. The substitution effect on labor supply weakly dominates the income effect for rule-of-thumb consumers so that they increase their labor supply only slightly. In contrast, Ricardian households are also subject to an additional negative wealth effect so that their increase in labor supply is more pronounced. The absolute change in labor supply is strongest among Ricardian households with little income who are characterized by the lowest productivity. ${ }^{37}$ In terms of percentage changes, however, the labor response is strongest among the high-productivity workers so that inequality of gross labor income increases. Moreover, Ricardian households decrease consumption while rule-of-thumb consumers increase consumption (see first two panels in row 3) leading to a decline in the Gini coefficent of consumption. In addition, all Ricardian households experience a decline in wealth due to the declining price of capital $q_{t}$ (see right panel in row 3) such that wealth inequality decreases.

In the case of tax financing (as presented by the bottom three rows in Fig. 4), the quantitative magnitudes of the aforementioned impulse responses are smaller for Ricardian households since the responses of both wages and returns are smaller than in the case of bond financing. The impulse responses of incomes of rule-ofthumb consumers, on the other hand, stay almost the same since these households increase their labor supply in comparison to the bond financing case (compare the

\footnotetext{
${ }^{37}$ Notice that we present the changes in labor supply in absolute values in order to facilitate reading.
} 
right panels in rows 2 and 5) so that gross labor market income of the RoT consumers is almost identical in the two financing cases.

\subsection{Welfare Effects}

In this section, we investigate the second main question of our paper: Which households benefit from bonds rather than tax funding of additional government expenditures and which households lose? For this reason, we compute the (remaining) ex-post lifetime utilities of all households at ages $s=1, \ldots, 240$ for each productivity and consumer types. Our welfare results for the case of bond (tax) financing are illustrated by the shaded (solid) lines in Fig. 5. In order to be able to interpret lifetime utility changes, we express our results as consumption equivalent changes $(\mathrm{CEC}) \cdot{ }^{38}$

In the first row of Fig. 5, we display the impulse responses of (discounted) lifetime utility of Ricardian households and rule-of-thumb consumers, respectively, that result from an unanticipated positive shock to government consumption of one standard deviation in period $t=1$ and zero thereafter. Since government consumption $G_{t}$ is auto-correlated, $G_{t}$ adjusts only gradually to its steady state value as depicted in Fig. 2. For Ricardian households, all productivity types experience a drop in lifetime utility irrespective of the financing form. Welfare losses amount to $0.012 \%$ - $0.157 \%$ of consumption depending on the individual's age when the shock occurs. In the period of the shock, labor of all Ricardian workers increases, while consumption of Ricardian households decreases for all ages (compare Fig. 4). Therefore, instantaneous utility in the period of the shock falls unanimously for all Ricardian households.

The majority of rule-of-thumb consumers also loses from extra government spending for both forms of government financing. Welfare losses are smaller than in the

\footnotetext{
${ }^{38}$ The consumption equivalent change is computed by the percentage number that steady-state consumption has to be changed so that the resulting lifetime utility (for given steady-state labor supply) is equal to the lifetime utility obtained in the case of stochastic government consumption.
} 

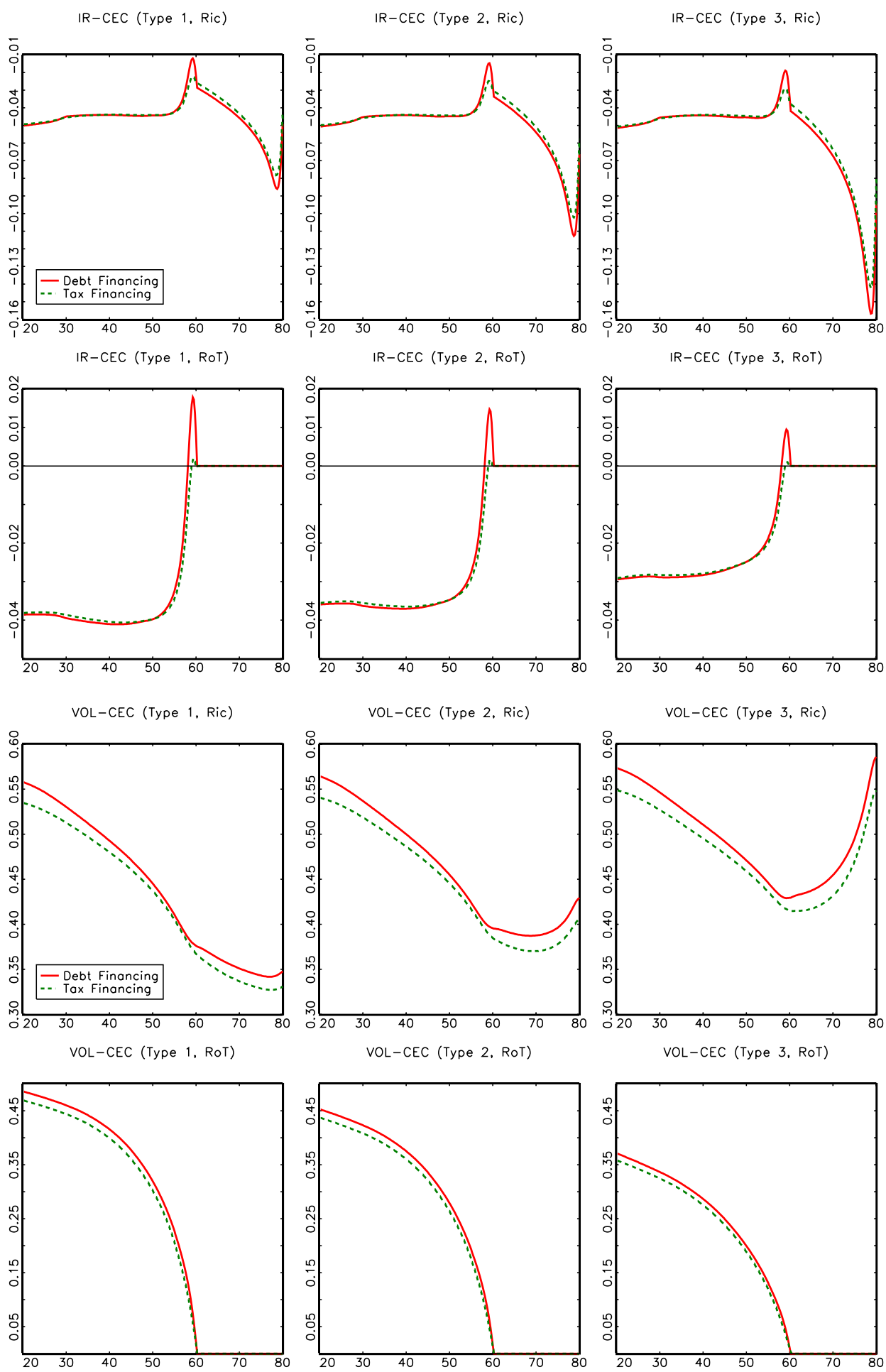

Figure 5: Impulse Responses and Volatilities for Consumption Equivalent Changes (CEC in \%) - Abscissa: Age in years. Types 1 to 3: Productivity types $j \in\{1,2,3\}$. 
case of the Ricardian households and only amount to a maximum of $0.041 \%$ of consumption, while households close to retirement even benefit from a debt-financed increase in government spending. The reason why rule-of-thumb households close to the retirement age of 60 years even experience an increase in welfare is explained by the increases of net wages. Higher net labor income raises consumption and instantaneous utility of rule-of-thumb consumers. In the following periods, the net wage rate declines and falls below its steady-state value. If workers are close to retirement, however, they do not suffer as much from theses wage decreases because they receive constant pensions beyond the age of 60 years. We also observe that the welfare losses of the Ricardian households are mainly larger than those of the rule-of-thumb consumers because of the reduction in the price of capital and the temporary decline of asset returns. ${ }^{39}$

In the case of a tax-financed increase in government spending (represented by the solid lines), welfare effects are more beneficial for young workers and retired Ricardian households, while they are more detrimental for rule-of-thumb and Ricardian workers close to retirement. The retired rule-of-thumb households are indifferent between the two forms of government financing because we have assumed pensions to be constant. Hence, Ricardian retirees and younger workers are better off if the increase in government spending is accompanied by an increase in taxes, while both rule-of-thumb and Ricardian workers close to retirement are worse off.

Bear in mind though that a decrease in government consumption is just as likely to occur as a spending increase since government spending follows an $\mathrm{AR}(1)$ process

\footnotetext{
${ }^{39}$ Notice that we have two non-Ricardian elements in our model so that Ricardian equivalence does not hold. On the one hand, we have rule-of-thumb consumers. On the other hand, lifetime is finite in our model and households are assumed not to be altruistic with respect to their children. As a consequence, they do not consider the loss in life-time utility of future generations that results from higher debt. The latter effect, however, is rather small in our model because we consider 240 periods and, according to Fig. 2, the real value of government debt under a debt-financed increase in government spending has already shrunk from the maximum deviation of $0.32 \%$ to $0.02 \%$ within the first 24 periods ( $=6$ years) after the shock. Therefore, only the very old households can pass on some of the extra debt to yet unborn generations.
} 
in our model. As the individuals' optimal form of financing depends on the sign of the shock by the symmetry of our solution, the optimal age-specific financing form of changes in government expenditures would therefore alternate between taxes and bonds. Such a policy, different responses of government finance depending on the outcome of the shock, however, would be infeasible in the long run. ${ }^{40}$ For these reasons, the most appropriate policy goal is stabilization. We simulate the model with stochastic government consumption over 5,000,0000 periods in order to study the effects of both financing forms on the volatility of (remaining) lifetime utilities. $^{41}$ The second row in Fig. 5 presents the corresponding standard deviations. Both Ricardian households and rule-of-thumb consumers at all ages display lower volatilities in lifetime utility under tax financing than under debt financing, irrespective of their productivity type. Notice, in particular, that the volatilities of older Ricardian households and rule-of-thumb consumers are also lower for tax-financed changes in government spending. Hence, and contrary to conventional wisdom, even retired Ricardian household are better off by tax funding because it entails smaller changes in capital prices and, hence, a lower volatility of their wealth over the life-cycle.

\section{Conclusion}

We have considered the distributional and welfare effects of unanticipated government spending shocks in a heterogeneous-agent extension of the standard New Keynesian model with two types of households, Ricardians and rule-of-thumb consumers. In addition to the consumer type, households differ with respect to their age and individual productivity so that our overlapping generations model is able to replicate the inequality of income and wealth observed empirically in the US economy. Fur-

\footnotetext{
${ }^{40}$ We would like to thank the editor and one anonymous referee for pointing this out and suggesting the following analysis of stabilization policies to us.

${ }^{41}$ Due to the high persistence of government spending shocks and the capital adjustment in our OLG-model, we observed that results stabilize after a time horizon of approximately 1,000,000 periods (quarters). We, therefore, used 5,000,000 periods in all our simulations.
} 
thermore, we have incorporated both the progressive US income tax system to better replicate the fiscal redistribution and a variable price of capital in order to take into account of the wealth effects that result from changes in government spending. Our results are as follows.

First, the analysis shows that an unanticipated increase in government spending decreases income and wealth inequality. In particular, an increase of one standard deviation in government consumption reduces the Gini coefficient of gross market income by $0.022 \%$ for both debt and tax financing. The quantitative effect on the wealth distribution is smaller and only amounts to a reduction of the Gini coefficient by $0.005 \%$ (tax financing) and $0.011 \%$ (bond financing). Notice that, even though the magnitude of the redistributive effect seems small on first inspection of the Gini coefficients, one needs to bear in mind that the Gini coefficient is an aggregate measure and, in our study, dismantles significant redistribution on the disaggregate level. In particular, an unanticipated increase in government spending financed by higher debt induces an increase of gross market income of Ricardian workers and Rule-of-Thumb consumers by $-0.02 \%$ to $+0.50 \%$, while it decreases the gross income of Ricardian pensioners by $0.01 \%$ to $0.52 \%$. As these two effects almost cancel out on the aggregate level, the Gini coefficients display little changes.

Second, we have analyzed how the financing form of stochastic government consumption affects the volatility of (remaining) life-time utility of the individual generations. We find that tax financing unambiguously results in lower utility fluctuations. Contrary to conventional wisdom, it is not only the very young households, but also the old retired households who benefit from tax financing of expenditures. Our result crucially depends on the assumption of a variable capital price. For a constant price of capital, none of the financing forms strictly dominates the other in terms of its role in stabilizing the volatility of generational welfare.

One should, however, be careful to use the welfare results from our fiscal policy experiment for normative implications. It seems that tax financing allows households to better smooth their consumption over the life-cycle. However, in our model, we rather consider the effects of stochastic government spending "shocks" in contrast 
to deliberate government stabilization policies. For this reason, the answer to the question "Should additional government expenditures be financed by taxes or debt?" also depends on the purpose of government expenditures. In addition, we find that bond financing implies a somewhat higher response of inflation and wages to an increase of government consumption than tax financing. Therefore, the form of financing might have additional effects on the welfare of households that we did not consider in this paper. In particular, we assume pensions to be constant over the business cycle. If pensions were adjusted for higher wages, retirees might advocate for bond financing instead. Moreover, we also assume that the nominal income tax schedule adjusts instantaneously to higher inflation so that we do not model the so-called "tax bracket creep" effect. Incorporating public pension policy and the tax bracket creep into the present model constitutes an interesting direction for future research. 


\section{References}

Afonso, A. and R. M. Sousa (2012). The Macroeconomic Effects of Fiscal Policy. Applied Economics $44(34), 4439-4454$.

Agnello, L. and R. M. Sousa (2013). Fiscal Policy And Asset Prices. Bulletin of Economic Research 65(2), $154-177$.

Aiyagari, S. R. (1994). Uninsured Idiosyncratic Risk and Aggregate Saving. The Quarterly Journal of Economics $109(3), 659$ - 684.

Altonij, J. G. (1986). Intertemporal Substitution in Labor Supply: Evidence from Micro Data. Journal of Political Economy 94(3), 176 - 215.

Anderson, E., A. Inoue, and B. Rossi (2016). Heterogeneous Consumers and Fiscal Policy Shocks. Journal of Money, Credit and Banking 48(8), 1877 - 1888.

Arias, E. (2014). United States Life Tables, 2010. National Vital Statistics Reports; vol 63 no 7. Hyattsville, MD: National Center for Health Statistics.

Barro, R. J. (1979). On the Determination of the Public Debt. Journal of Political Economy 87(5), 940-971.

Basu, S. and M. S. Kimball (1997). Cyclical Productivity with Unobserved Input Variation. NBER Working Paper 5915.

Baxter, M. and D. D. Farr (2005). Variable Capital Utilization and International Business Cycles. Journal of International Economics 65(2), 335 - 347.

Benabou, R. (2002). Tax and Education Policy in a Heterogeneous-Agent Economy: What Levels of Redistribution Maximize Growth and Efficiency? Econometrica $70(2), 481-517$.

Blanchard, O. and R. Perotti (2002). An Empirical Characterization of the Dynamic Effects of Changes in Government Spending and Taxes on Output. The Quarterly Journal of Economics 117(4), 1329 - 1368.

Brinca, P., H. H. Holter, P. Krusell, and L. Malafry (2016). Fiscal Multipliers in the 21st Century. Journal of Monetary Economics $77(\mathrm{C}), 53-69$.

Budría Rodríguez, S., J. Díaz-Giménez, V. Quadrini, and J.-V. Ríos-Rull (2002). Updated Facts on the U.S. Distributions of Earnings, Income, and Wealth. Federal Reserve Bank of Minneapolis - Quarterly Review, 2 - 35. 
Cagetti, M. and M. de Nardi (2009). Estate Taxation, Entrepreneurship, and Wealth. American Economic Review 99(1), 85 - 111.

Campbell, J. Y. and N. G. Mankiw (1989). Consumption, Income and Interest Rates: Reinterpreting the Time Series Evidence. In NBER Macroeconomics Annual 1989, Volume 4, NBER Chapters, pp. $185-246$.

Campbell, J. Y. and N. G. Mankiw (1991). The Response of Consumption to Income: A Cross-country Investigation. European Economic Review 35(4), 723 - 756.

Chang, B. H., Y. Chang, and S.-B. Kim (2016). Pareto Weights in Practice: A Quantitative Analysis Across 32 OECD Countries. Working Paper.

Chatterjee, S. and S. J. Turnovsky (2012). Infrastructure and Inequality. European Economic Review 56(8), 1730-1745.

Christiano, L. J., M. Eichenbaum, and C. L. Evans (2005). Nominal Rigidities and the Dynamic Effects of a Shock to Monetary Policy. Journal of Political Economy 113(1), 1 - 45.

Christoffel, K., K. Kuester, and T. Linzert (2009). The Role of Labor Markets for Euro Area Monetary Policy. European Economic Review 53(8), 908 - 936.

De Giorgi, G. and L. Gambetti (2012). The Effects of Government Spending on the Distribution of Consumption. Working Paper.

De Nardi, M. (2015). Quantitative Models of Wealth Inequality: A Survey. NBER Working Paper 21106.

De Nardi, M. and F. Yang (2016). Wealth inequality, Family Background, and Estate Taxation. Journal of Monetary Economics 77 (C), 130 - 145.

Fatás, A. and I. Mihov (2001). The Effects of Fiscal Policy on Consumption and Employment: Theory and Evidence. CEPR Discussion Papers 2760, C.E.P.R. Discussion Papers.

Fernández-Villaverde, J. and D. Krueger (2007). Consumption over the Life Cycle: Facts from Consumer Expenditure Survey Data. The Review of Economics and Statistics $89(3), 552-565$.

Ferriere, A. and G. Navarro (2016). The Heterogeneous Effects of Government Spending: It's All About Taxes. Working Paper. 
Fisher, J. D. M. and R. Peters (2010). Using Stock Returns to Identify Government Spending Shocks. Economic Journal 120(544), $414-436$.

Galí, J., J. D. Lopez-Salido, and J. Vallés (2007). Understanding the Effects of Government Spending on Consumption. Journal of the European Economic Association 5(1), $227-270$.

Giordani, P. and P. Söderlind (2004). Solution of Macromodels with Hansen-Sargent Robust Policies: Some Extensions. Journal of Economic Dynamics and Control 28(12), $2367-2397$.

Gomme, P., B. Rvaikumar, and P. Rupert (2011). The Return to Capital and the Business Cycle. Review of Economic Dynamics 14(2), 262 - 278.

Guiso, L., M. Haliassos, and T. Jappelli (2002). Household Portfolios (1st ed.). Massachusetts Institute of Technology: MIT Press.

Hall, R. E. (2005). Employment Fluctuations with Equilibrium Wage Stickiness. American Economic Review 95(1), 50 - 65.

Hansen, G. and S. Imrohoroğlu (2008). Consumption over the Life Cycle: The Role of Annuities. Review of Economic Dynamics 11(3), 566 - 583.

Hansen, G. D. (1993). The Cyclical and Secular Behaviour of the Labour Input: Comparing Efficiency Units and Hours Worked. Journal of Applied Econometrics $8(1), 71-80$.

Heathcote, J., K. Storesletten, and G. L. Violante (2016). Optimal Tax Progressivity: An Analytical Framework. Quarterly Journal of Economics (forthcoming).

Heer, B. and A. Maußner (2009). Dynamic General Equilibrium Modeling: Computational Methods and Applications (2nd ed.). Heidelberg: Springer.

Huggett, M. (1996). Wealth Distribution in Life-Cycle Economies. Journal of Monetary Economics 38(3), 469 - 494.

Iacoviello, M. and M. Pavan (2013). Housing and Debt over the Life Cycle and over the Business Cycle. Journal of Monetary Economics 60(2), 221 - 238.

Killingsworth, M. R. (1983). Labor Supply. Cambridge, MA: Cambridge University Press. 
Krause, M. U. and T. A. Lubik (2007). The (Ir)relevance of Real Wage Rigidity in the New Keynesian Model with Search Frictions. Journal of Monetary Economics 54(3), $706-727$.

Krueger, D. and F. Perri (2006). Does Income Inequality Lead to Consumption Inequality? Evidence and Theory. Review of Economic Studies 73(1), 163 - 193.

Krueger, D., F. Perri, L. Pistaferri, and G. L. Violante (2010). Cross Sectional Facts for Macroeconomists. Review of Economic Dynamics 13(1), 1-14.

Luo, Y., J. Nie, and E. R. Young (2014). Model uncertainty and intertemporal tax smoothing. Journal of Economic Dynamics and Control 45(C), 289-314.

MaCurdy, T. E. (1981). An Empirical Model of Labor Supply in a Life-Cycle Setting. Journal of Political Economy 89(6), 1059 - 1085.

Mendoza, E. G., A. Razin, and L. L. Tesar (1994). Effective Tax Rates in Macroeconomics: Cross-country Estimates of Tax Rates on Factor Incomes and Consumption. Journal of Monetary Economics 34(3), 297 - 323.

Monacelli, T., R. Perotti, and A. Trigari (2010). Unemployment Fiscal Multipliers. Journal of Monetary Economics 57(5), 531 - 553.

Murphy, D. and K. J. Walsh (2016). Spending Shocks and Interest Rates. Working Paper.

OECD (2007). Pensions at a Glance: Public Policies across OECD Countries. OECD Publishing.

Quadrini, V. (2000). Entrepreneurship, Saving and Social Mobility. Review of Economic Dynamics 3(1), $1-40$.

Ramey, V. A. (2011). Identifying Government Spending Shocks: It's all in the Timing. The Quarterly Journal of Economics 126(1), 1 - 50.

Ramey, V. A. and M. D. Shapiro (1998). Costly capital reallocation and the effects of government spending. Carnegie-Rochester Conference Series on Public Policy 48(1), $145-194$.

Ravn, M. O., S. Schmitt-Grohé, and M. Uribe (2012). Consumption, government spending, and the real exchange rate. Journal of Monetary Economics 59(3), 215 -234 . 
Rotemberg, J. J. and M. Woodford (1992). Oligopolistic Pricing and the Effects of Aggregate Demand on Economic Activity. Journal of Political Economy 100(6), $1153-1207$.

Schmitt-Grohé, S. and M. Uribe (2006). Optimal Fiscal and Monetary Policy in a Medium-Scale Macroeconomic Model. In NBER Macroeconomics Annual 2005, Volume 20, NBER Chapters, pp. 383-462. National Bureau of Economic Research, Inc.

Schmitt-Grohé, S. and M. Uribe (2007). Optimal Simple and Implementable Monetary and Fiscal Rules. Journal of Monetary Economics 54(6), 1702 - 1725.

Shapiro, M. D. and J. Slemrod (1995). Consumer Response to the Timing of Income: Evidence from a Change in Tax Withholding. American Economic Review 85(1), $274-283$.

Trabandt, M. and H. Uhlig (2011). The Laffer Curve Revisited. Journal of Monetary Economics 58(4), $305-327$.

Uhlig, H. (2007). Explaining Asset Prices with External Habits and Wage Rigidities in a DSGE Model. American Economic Review 97(2), 239 - 243.

Walsh, C. E. (2005). Labor Market Search, Sticky Prices, and Interest Rate Policies. Review of Economic Dynamics 8(4), 829 - 849. 


\section{Appendix}

\section{A.1 Mathematical Derivations}

\section{A.1.1 Price Setting}

Firms choose their optimal nominal prices in a staggered fashion, according to Calvo (1983). There are two types of firms indexed by " $A$ " and " $N$ " in each period $t$. Type $A$ firms set their optimal relative price $\frac{P_{i, t}}{P_{t}}=\frac{P_{A, t}}{P_{t}}$ by solving an inter-temporal optimization problem, whereas type $N$ firms are only allowed to adjust their price in period $t$ according to a simple rule of thumb (7).

The probability of being a firm of type $A$ in period $t$ is given by $(1-\varphi)$. Hence, firms that are allowed to set their optimal price $\frac{P_{A, t}}{P_{t}}$ in period $t$ solve a standard maximization problem: ${ }^{42}$

$$
\begin{aligned}
& \max _{P_{A, t} / P_{t}} E_{t} \sum_{s=0}^{\infty} \varphi^{s} z_{t+s}\left[\left(\frac{\pi^{s} P_{A, t}}{P_{t+s}}\right) Y_{A, t+s}-g_{t+s}\left(Y_{A, t+s}+F\right)\right] \\
& \text { s.t. } Y_{A, t+s}=\left(\frac{\pi^{s} P_{A, t}}{P_{t+s}}\right)^{-\epsilon} Y_{t+s},
\end{aligned}
$$

where the stochastic discount factor of the households $z_{t+i}$ is defined as

$$
z_{t+s} \equiv \frac{1}{\prod_{l=1}^{s}\left(R_{t+l-1}^{b} / \pi_{t+l}\right)} .
$$

We get, after some tedious algebra, the following first-order condition:

$$
0=E_{t} \sum_{s=0}^{\infty} \varphi^{s} z_{t+s} Y_{A, t+s}\left(\frac{\pi^{s}}{\prod_{l=1}^{s} \pi_{t+l}} \frac{P_{A, t}}{P_{t}}-\frac{\epsilon}{\epsilon-1} g_{t+s}\right) .
$$

This condition states that the optimal relative price must be chosen in such a manner that discounted real marginal cost equal discounted real marginal revenues. Moreover, it can easily be shown that the term $\epsilon /(1-\epsilon)$ defines the gross price mark-up in a steady state with an inflation of zero. The realized (aggregate) profit $\Omega_{t}$ in period $t$ is given by

$$
\Omega_{t}=\int_{0}^{1}\left(\frac{P_{i, t}}{P_{t}} Y_{i, t}-w_{t} N_{i, t}-r_{t} u_{t} K_{i, t}\right) d i=\int_{0}^{1}\left(\frac{P_{i, t}}{P t} Y_{i, t}-g_{t}\left(Y_{i, t}+F\right)\right) d i,
$$

\footnotetext{
${ }^{42}$ Since all intermediate goods firms that are allowed to set their price optimally in period $t$ are identical, we can drop the firm index $i$ from the following equations.
} 
and the aggregate price level evolves according to the following equation:

$$
P_{t}^{1-\epsilon}=(1-\varphi) P_{A, t}^{1-\epsilon}+\varphi\left(\pi P_{t-1}\right)^{1-\epsilon}
$$

Aggregate production $Y_{t}$ as presented in (2) and total production in the intermediate goods sector $\tilde{Y}_{t}$

$$
\tilde{Y}_{t}=N_{t}^{1-\alpha}\left(u_{t} K_{t}\right)^{\alpha}-F
$$

are related by the following equation:

$$
Y_{t}=\frac{1}{q_{t}^{p}} \tilde{Y}_{t}
$$

where $q_{t}^{p}$ measures the price dispersion in the intermediate goods sector and evolves according to the following dynamic equation:

$$
q_{t}^{p}=(1-\varphi)\left(\frac{P_{A, t}}{P_{t}}\right)^{-\epsilon}+\varphi\left(\frac{\pi_{t}}{\pi}\right)^{\epsilon} q_{t-1}^{p} .
$$

The first-order condition of this price-setting problem is represented by

$$
\frac{P_{A, t}}{P_{t}} \cdot \Gamma_{2 t}=\frac{\epsilon}{\epsilon-1} \cdot \Gamma_{1 t}
$$

where

$$
\begin{aligned}
& \Gamma_{1 t}=g_{t} Y_{t}\left(\frac{P_{A, t}}{P_{t}}\right)^{-\epsilon}+\varphi z_{t+1}\left(\frac{\pi\left(P_{A, t} / P_{t}\right)}{\pi_{t+1}\left(P_{A, t+1} / P_{t+1}\right)}\right)^{-\epsilon} \Gamma_{1 t+1}, \\
& \Gamma_{2 t}=Y_{t}\left(\frac{P_{A, t}}{P_{t}}\right)^{-\epsilon}+\varphi z_{t+1}\left(\frac{P_{A, t} / P_{t}}{P_{A, t+1} / P_{t+1}}\right)^{-\epsilon}\left(\frac{\pi}{\pi_{t+1}}\right)^{1-\epsilon} \Gamma_{2 t+1} .
\end{aligned}
$$

In steady state, we assume that profits are equal to zero. Hence, the fixed cost $F$ is given by

$$
F=\frac{1-g}{g} Y
$$

where marginal cost amount to

$$
g=\frac{\epsilon-1}{\epsilon} .
$$




\section{A.1.2 Capital Producers}

The production technology (11) implies

$$
\begin{aligned}
\frac{d \Omega_{t}^{c}}{d I_{t}} & =q_{t} K_{t} \frac{a_{1}(1-\zeta)}{1-\zeta}\left(\frac{I_{t}^{D}}{K_{t}}\right)^{-\zeta} \frac{1}{K_{t}}-1, \\
& \Rightarrow q_{t}=\frac{1}{a_{1}}\left(\frac{I_{t}^{D}}{K_{t}}\right)^{\zeta} . \\
\frac{d \Omega_{t}^{c}}{d K_{t}} & =q_{t}\left(\frac{a_{1}}{1-\zeta}\left(\frac{I_{t}^{D}}{K_{t}}\right)^{1-\zeta}+a_{2}\right)-r_{t}^{c}, \\
& \Rightarrow r_{t}^{c s}=q_{t}\left(\frac{a_{1} \zeta}{1-\zeta}\left(\frac{I_{t}}{K_{t}}\right)^{1-\zeta}+a_{2}\right) .
\end{aligned}
$$

Thus, profits are always equal to zero:

$$
\begin{aligned}
\Omega_{t}^{c} & =q_{t} f\left(I_{t}^{D} / K_{t}\right) K_{t}-I_{t}^{D}-r_{t}^{c s} K_{t}, \\
& =q_{t} f\left(I_{t}^{D} / K_{t}\right) K_{t}-I_{t}^{D}-q_{t}\left(f\left(I_{t}^{D} / K_{t}\right)-f^{\prime}\left(I_{t}^{D} / K_{t}\right) \frac{I_{t}^{D}}{K_{t}}\right) K_{t}, \\
& =q_{t} f\left(I_{t}^{D} / K_{t}\right) K_{t}-I_{t}^{D}-q_{t} f\left(I_{t}^{D} / K_{t}\right) K_{t}+I_{t}^{D}, \\
& =0 .
\end{aligned}
$$

In steady state, $q=1$ and $f(\delta)=\delta$ yield

$$
\begin{aligned}
a_{1} & =\delta^{\zeta}, \\
a_{2} & = \begin{cases}-\frac{\delta \zeta}{1-\zeta}, & \text { for } 1 \neq \zeta>0, \\
\delta-\ln \left(\delta^{\delta}\right), & \text { for } \zeta=1,\end{cases} \\
r^{c s} & =0
\end{aligned}
$$

\section{A.1.3 Capital Utilization}

With $\delta\left(u_{t}\right)$ given by (17) and the interest rate $r_{t}^{i s}$ from (6b), the optimal utilization rate implied by the household's first-order condition $(24 \mathrm{e})$ is given by

$$
u_{t}=\left(\frac{\alpha g_{t}}{q_{t} \delta_{1}\left(1+\epsilon_{u}\right)}\left(\frac{K_{t}}{N_{t}}\right)^{\alpha-1}\right)^{1 /\left(1+\epsilon_{u}-\alpha\right)} .
$$

In steady state, $u=1$ and $\delta(1)=\delta$ imply

$$
\begin{aligned}
& \delta_{1}=\left(\frac{\alpha g}{q\left(1+\epsilon_{u}\right)}\right)\left(\frac{N}{K}\right)^{1-\alpha}, \\
& \delta_{0}=\delta-\delta_{1} .
\end{aligned}
$$




\section{A.2 U.S. tax rates on labor and capital income}

Fig. A.1 displays the time series of labor and capital income tax rates, $\tau^{w}$ and $\tau^{r}$. Evidently, the two series are positively correlated.

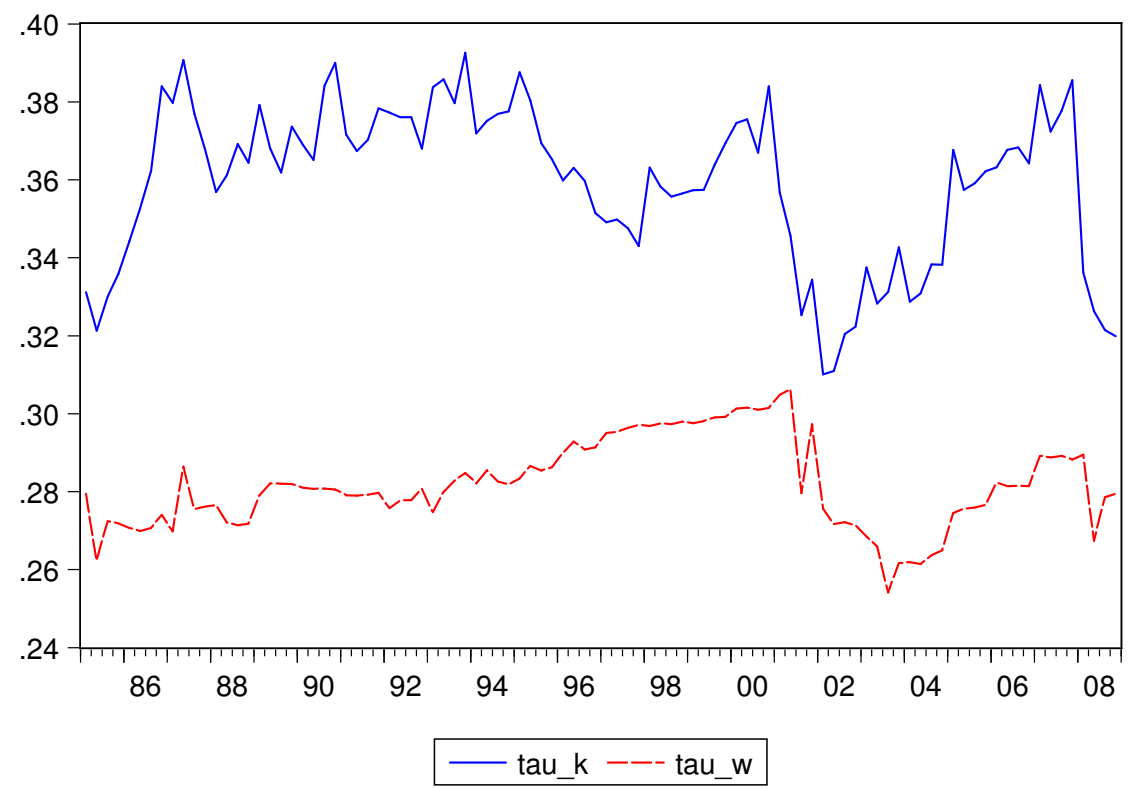

Figure A.1: U.S. Tax Rates on Labor (tau_w) and Capital (tau_k) Income. Source: Gomme et al. (2011).

\section{A.3 Sensitivity Analysis}

\section{A.3.1 Price of Capital}

The elasticity $\zeta$ of adjustment costs $f(I / K)$ with respect to the investment-capital ratio $I / K$ according to (13a) is crucial for the wealth channel in our model. It controls the dynamics of the price of capital $q_{t}$ that are caused by government spending shocks. We have calibrated the value $\zeta=1$ in line with Galí et al. (2007). The sensitivity of our results with respect to the elasticity $\zeta \in\{0,4\}$ is illustrated in Figs. A.2 and A.3.

For $\zeta=4$, the effects on the Gini coeffcients remain quantitatively and qualitatively similar in comparison to our benchmark calibration (see the two upper panels of Fig. A.2 and Fig. 3). Moreover, our qualitative result that volatilities of lifetime utilities are lower across all living generations under tax financing is also confirmed 
by the two upper panels of Fig. A.3. If we set $\zeta=0$ instead, all households face a constant price of capital. In this case, the inequality in gross market income also decreases irrespective of the financing form (see left panel in the third row of Fig. A.2). Under tax financing, the Gini coefficients for wealth and consumption increase, while the response of the Gini coefficient of gross labor income is initially slightly positive end becomes negative in the subsequent periods. In contrast, debt financing implies qualitative similar result for gross market income and gross labor income, whereas wealth and consumption inequality increases after a temporary decline when the shock occurs. In addition, the two bottom panels in A.3 show that tax-financed changes in government consumption imply lower volatilities for both Ricardian workers up to an age of 50 years and rule-of-thumb consumers, while older Ricardian workers and retirees face higher volatilities in comparison to the debt financing case.

\section{A.3.2 Rule-of-thumb Consumers}

In this section, we conduct a sensitivity analysis of our results for inequality and welfare with respect to the share of rule-of-thumb consumers $v_{R o T} \in\{0.5,0.35\}$.

The effects on inequality are qualitatively the same, according to Fig. A.4, in both financing forms except for the Gini coefficient of gross market which increases slightly under debt financing in the second period (when the shock occurs) but also decreases in the following periods. Figure A.5 displays the corresponding volatilities of (remaining) lifetime utilities. If the share of rule-of-thumb consumers increases to $v_{R o T}=0.50$, then our results remain almost identical with respect to our benchmark case with $v_{R o T}=0.43$. All households show a lower volatility in lifetime utility under tax financing than under debt financing. In contrast, if the share of rule-of-thumbers decreases to to $v_{R o T}=0.35$, the volatilities remain almost the same for Ricardian workers close to retirement, while consumption of the other Ricardian households and rule-of-thumb consumers displays lower volatilities under tax financing.

\section{A.3.3 Age Profile of the Capital Portfolio Share}

In this section, we provide a sensitivity analysis with respect to a more realistic calibration of individual portfolio shares over the life cycle and show that our results remain qualitatively the same. 


$$
\zeta=4:
$$

Gini - Gross Market Inc.
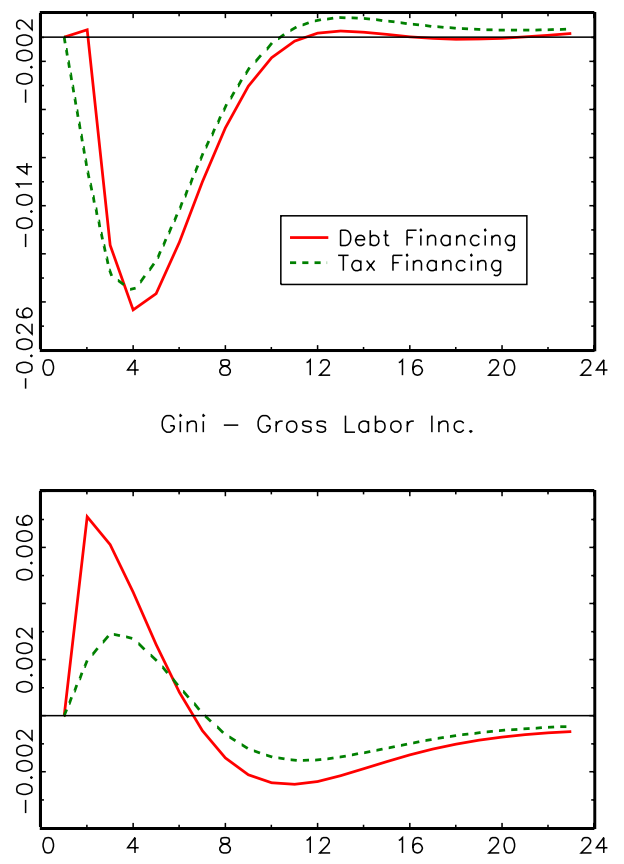

$\zeta=0$

Gini - Gross Market Inc.
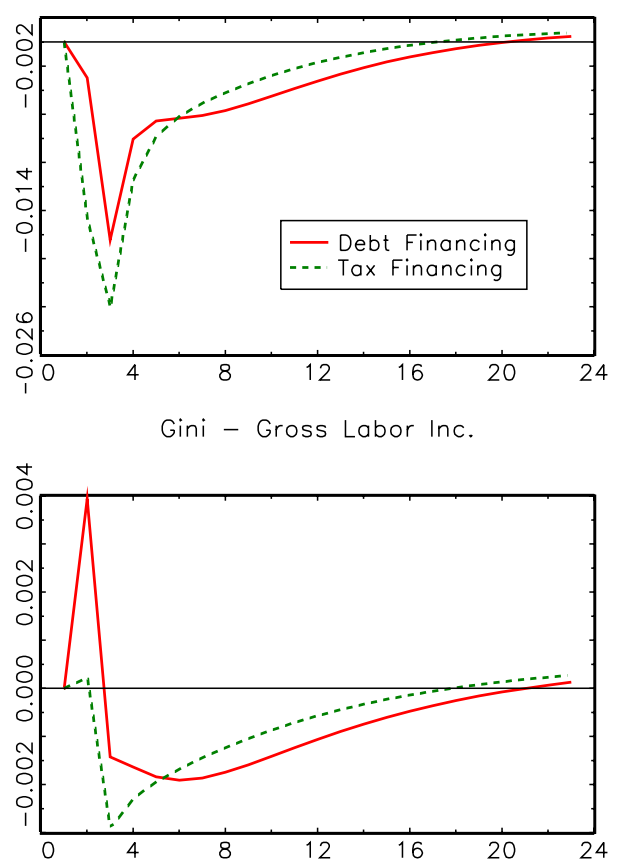

Gini - Wealth
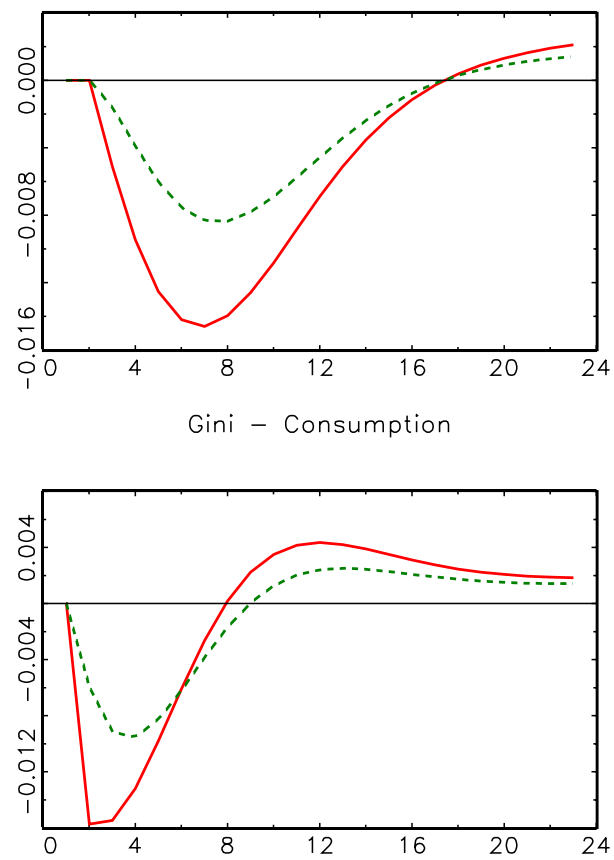

Gini - Wealth
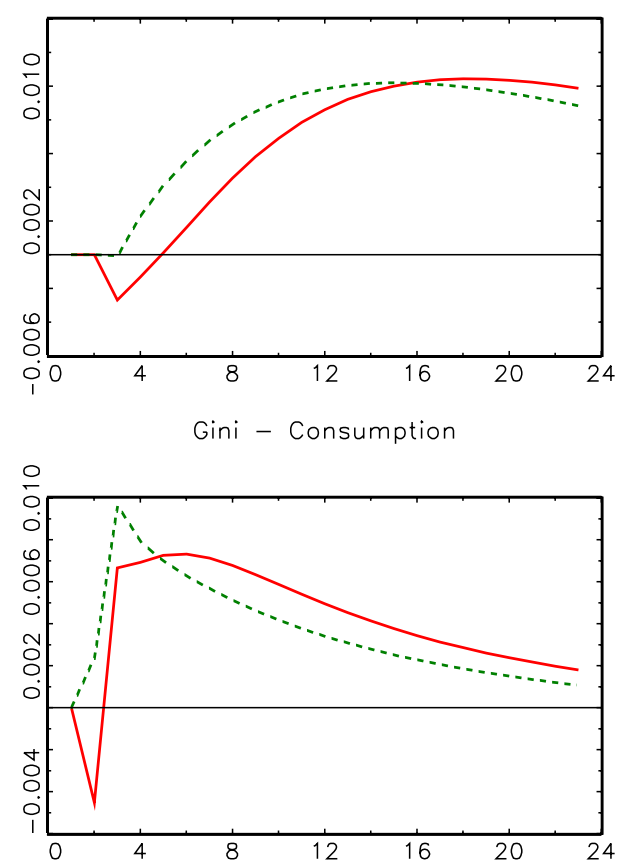

Figure A.2: Sensitivity Analysis: Price of Capital. Impulse responses of Gini Coefficients (percent deviations) - Abscissa: Periods after shock in $t=2$. 
Assumptions: Remember that total individual expenditures for assets at age $s+1$ in the steady state of our model are given by ${ }^{43}$

$$
a_{j}^{s+1}=q k_{j}^{s+1}+q^{b} b_{j}^{s+1}
$$

where $q^{b}=1 / R^{b}$ denotes the real pice of bonds. Thus, the share of risky assets $\chi^{s+1}$ at age $s+1$ in a portfolio amounts to

$$
\chi^{s+1}=\frac{q k_{j}^{s+1}}{a_{j}^{s+1}}
$$

and the share $\left(1-\chi^{s+1}\right)$ of bonds can be expressed as

$$
1-\chi^{s+1}=\frac{q_{t}^{b} b_{j}^{s+1}}{a_{j}^{s+1}} .
$$

In the steady state, we assume that theses shares are exogenously given and do not depend on the productivity type. Hence,

$$
k_{j}^{s+1}=\frac{\chi^{s+1} a_{j}^{s+1}}{q}
$$

and

$$
b_{j}^{s+1}=\frac{\left(1-\chi^{s+1}\right) a_{j}^{s+1}}{q^{b}}=\left(1-\chi^{s+1}\right) R^{b} a_{j}^{s+1} .
$$

Moreover, the assumptions above imply that aggregate capital and especially bond holdings are endogenous variables in the steady state:

$$
\begin{aligned}
K & =\sum_{s=1}^{T} \sum_{j=1}^{3} v_{r t c} \psi_{s-1} v_{j} k_{j}^{s}, \\
& =\sum_{s=1}^{T} \sum_{j=1}^{3} v_{r t c} \psi_{s-1} v_{j} \frac{\chi^{s} a_{j}^{s}}{q}
\end{aligned}
$$

and

$$
\begin{aligned}
B & =\sum_{s=1}^{T} \sum_{j=1}^{3} v_{r t c} \psi_{s-1} v_{j} b_{j}^{s}, \\
& =\sum_{s=1}^{T} \sum_{j=1}^{3} v_{r t c} \psi_{s-1} v_{j} \frac{\left(1-\chi^{s}\right) a_{j}^{s}}{q^{b}} .
\end{aligned}
$$

${ }^{43}$ For convenience the time index has been dropped from equations describing the steady state. 
For the computation of the dynamics in our model, our solution concept (first-order approximation around the steady state) only allows us to determine aggregate wealth in period $t+1$ which is given by

$$
A_{t+1}=\sum_{s=1}^{T} \sum_{j=1}^{3} v_{r t c} \psi_{s} v_{j} a_{t+1, j}^{s+1} .
$$

Moreover, the government budget (32) and, especially, the corresponding fiscal rule (34) control the evolution of aggregate government debt $B_{t+1}$ in period $t+1$. This, in turn, implies aggregate capital holdings:

$$
K_{t+1}=\frac{A_{t+1}-q_{t}^{b} B_{t+1}}{q_{t}}
$$

where $q_{t}^{b}=1 / R_{t}^{b}$. Therefore, we introduce the parameter $\kappa_{t+1}$ which governs the evolution of the portfolio share $\chi^{s}$ over time:

$$
\chi_{t+1}^{s+1}=\kappa_{t+1} \chi^{s+1} .
$$

Thus, the individual bond and capital holdings amount to

$$
k_{t+1, j}^{s+1}=\frac{\left(\kappa_{t+1} \chi^{s+1}\right) a_{t+1, j}^{s+1}}{q_{t}}
$$

and

$$
b_{t+1}^{s+1}=\frac{\left(1-\kappa_{t+1} \chi^{s+1}\right) a_{t+1, j}^{s+1}}{q_{t}^{b}} .
$$

Moreover, aggregate capital can also be expressed as

$$
\begin{aligned}
K_{t+1} & =\sum_{s=1}^{T} \sum_{j=1}^{3} v_{r t c} \psi_{s} v_{j} k_{t+1, j}^{s+1}, \\
& =\sum_{s=1}^{T} \sum_{j=1}^{3} v_{r t c} \psi_{s} v_{j} \frac{\left(\kappa_{t+1} \chi^{s+1}\right) a_{t+1, j}^{s+1}}{q_{t}} . \\
& =\kappa_{t+1} \sum_{s=1}^{T} \sum_{j=1}^{3} v_{r t c} \psi_{s} v_{j} \frac{\chi^{s+1} a_{t+1, j}^{s+1}}{q_{t}} .
\end{aligned}
$$

Hence, the variable $\kappa_{t+1}$ evolves according to

$$
\begin{aligned}
\kappa_{t+1} & =\frac{\frac{1}{q_{t}}\left(A_{t+1}-q_{t}^{b} B_{t+1}\right)}{\sum_{s=1}^{T} \sum_{j=1}^{3} v_{r t c} \psi_{s} v_{j} \frac{\chi^{s+1} a_{t+1}^{s+1}}{q_{t}}}, \\
& =\frac{\left(A_{t+1}-q_{t}^{b} B_{t+1}\right)}{\sum_{s=1}^{T} \sum_{j=1}^{3} v_{r t c} \psi_{s} v_{j} \chi^{s+1} a_{t+1}^{s+1}} .
\end{aligned}
$$


In the steady state, $\kappa$ is equal to 1.

Calibration and Results: With regard to the calibration, we use the age-specific shares $\chi^{s+1}$ of risky assets in total financial asset for the year 1998 that are provided by Guiso et al. (2002) and replicated in Table A.1 for the readers' convenience. Since government debt is an exogenous variable in our model, we scale these shares by a constant so that we are able to match the ratio of government debt to quarterly GDP in Brinca et al. (2016). Consequently, we are able to model the relative portfolio shares of capital between generations, and the share of capital is highest among the 55-64 year-old in both our model and empirically. Figs. A.6 and A.7 display the effects of the more realistic hump-shaped portfolio shares of capital over the life-cycle on our results with respect to our benchmark model. Our results remain qualitatively the same. In particular, we derive the following:

1. Income and wealth inequality improves in response to unexpected higher government expenditures, and consumption inequality declines, too.

2. Tax financing of additional expenditures reduces the volatility of (remaining) life-time utility for all generations and productivity types.

\begin{tabular}{|c|cccccc|}
\hline Age & $<35$ & $35-44$ & $45-54$ & $55-64$ & $65-74$ & $>75$ \\
\hline Share of Risky Assets & 36.0 & 44.4 & 52.7 & 56.8 & 50.4 & 43.4 \\
\hline
\end{tabular}

Table A.1: Riskiness of household portfolios with respect to total assets, by age of household head. Year: 1998. See also Guiso et al. (2002), page 200. 


$$
\zeta=4:
$$

VOL-CEC (Type 1, Ric)

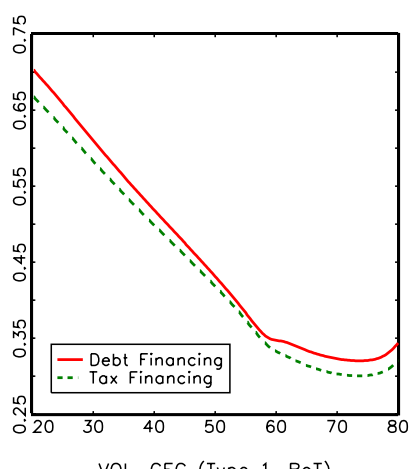

VOL-CEC (Type 1, RoT)

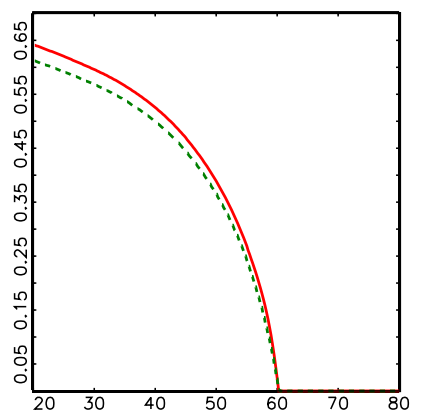

$\zeta=0$
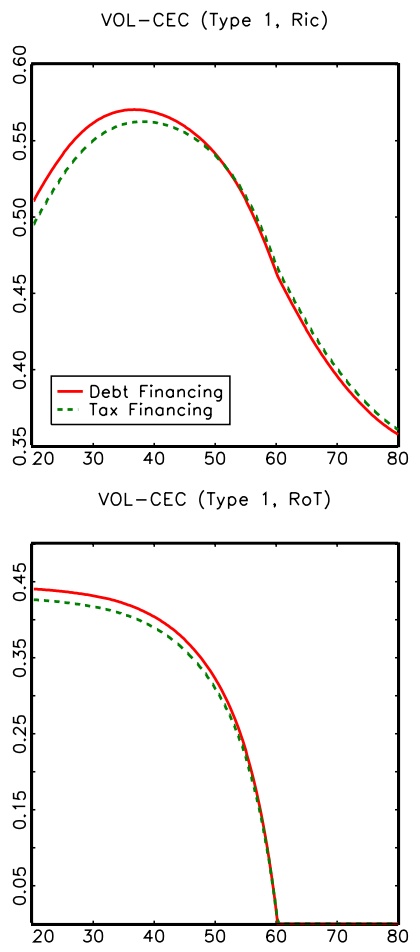

VOL-CEC (Type 2, Ric)

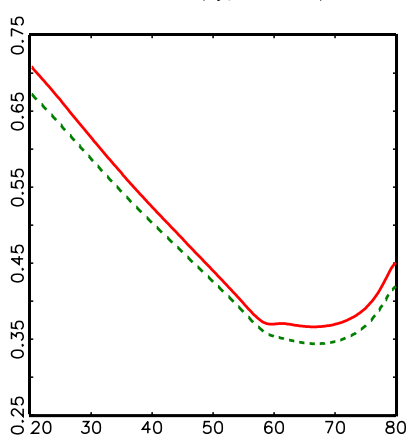

VOL-CEC (Type 2, RoT)

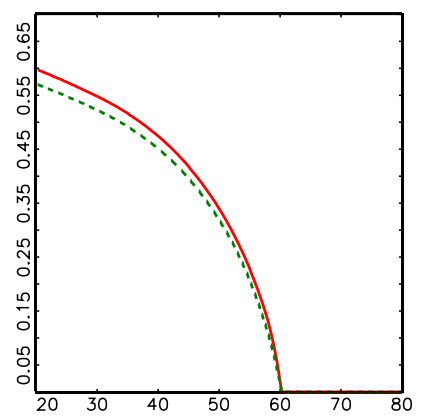

VOL-CEC (Type 2, Ric)

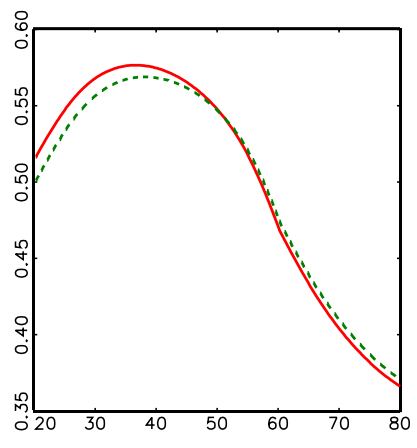

VOL-CEC (Type 2, RoT)

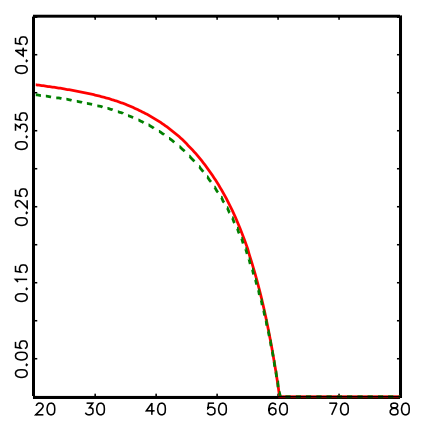

VOL-CEC (Type 3, Ric)

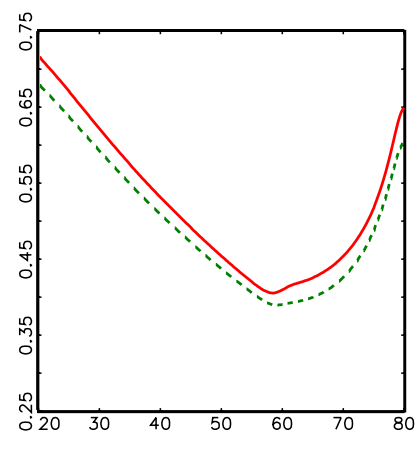

VOL-CEC (Type 3, RoT)
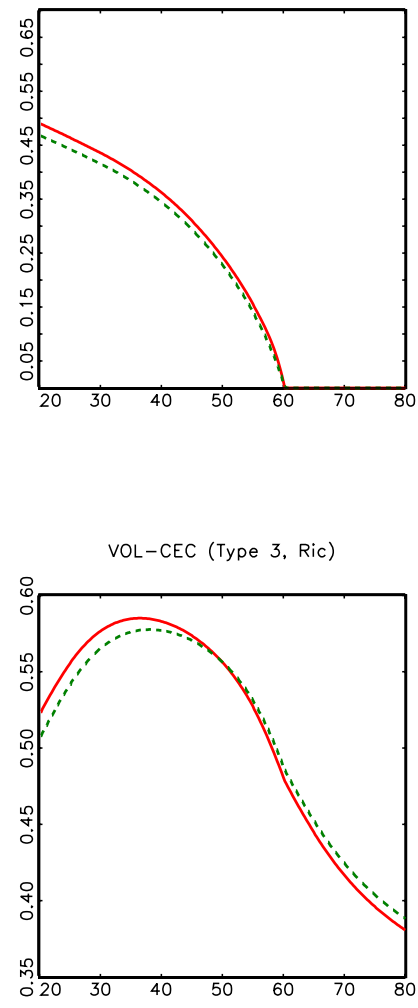

VOL-CEC (Type 3, RoT)

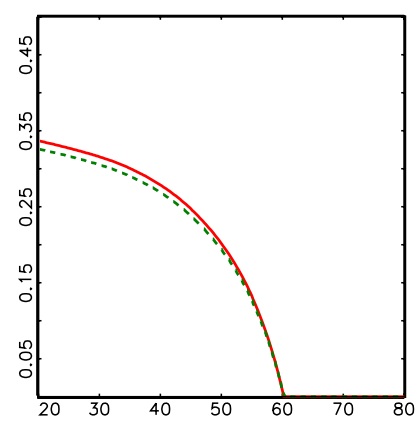

Figure A.3: Sensitivity Analysis: Price of Capital. Volatilities for Consumption Equivalent Changes (CEC in \%) - Abscissa: Age in years. Types 1 to 3: Productivity types $j \in\{1,2,3\}$. 
$v_{\text {RoT }}=0.50$ :

Gini - Gross Market Inc.
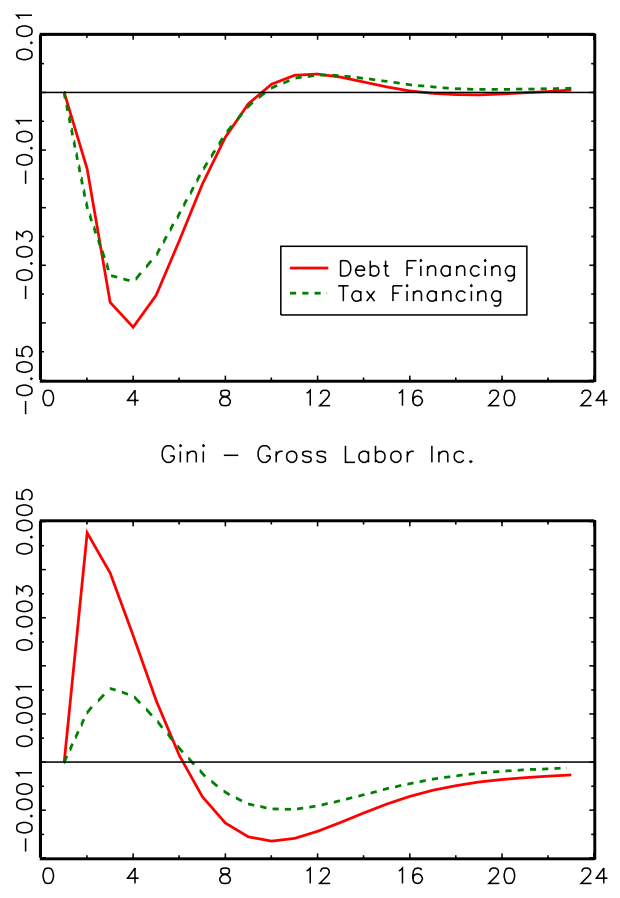

$v_{\text {RoT }}=0.35$ :

Gini - Gross Market Inc.
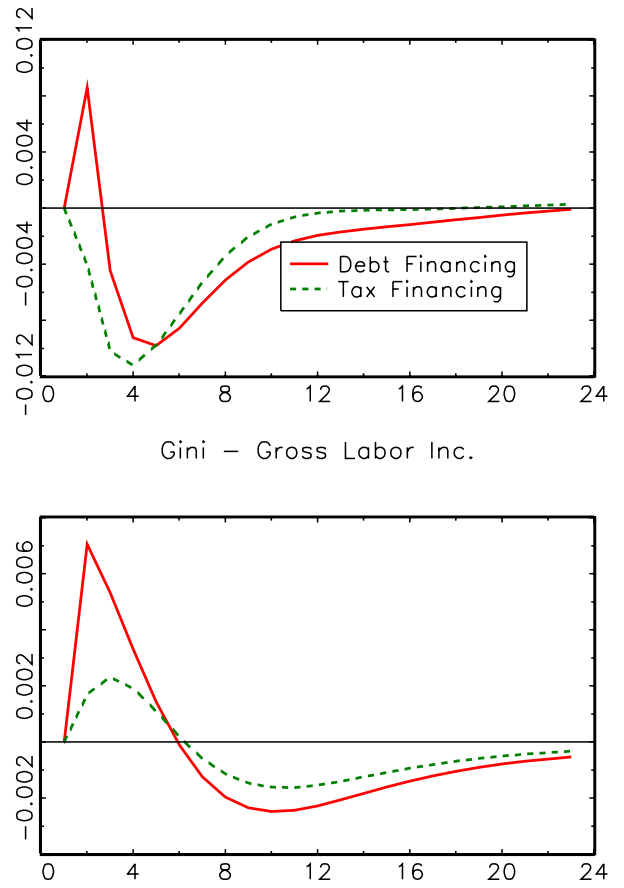

Gini - Wealth
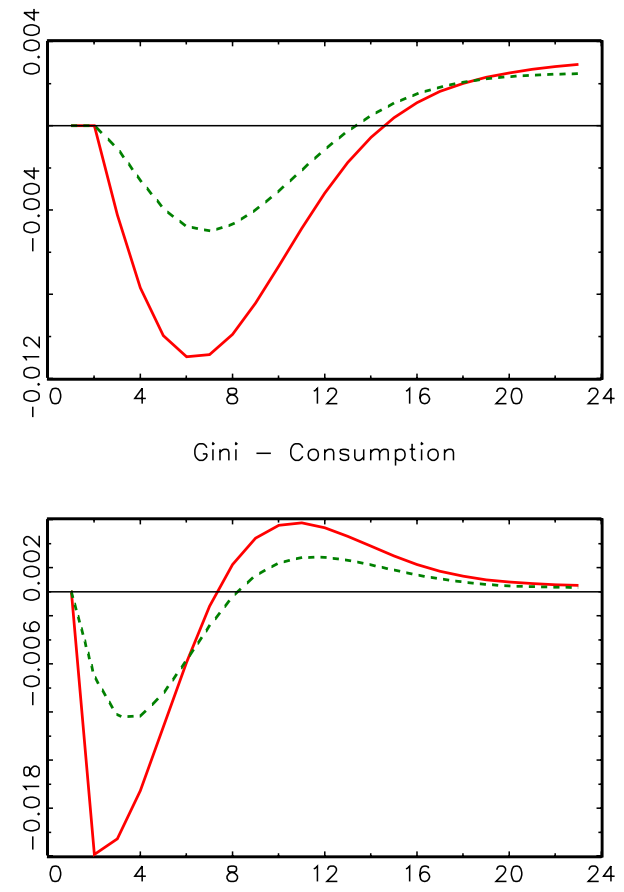

Gini - Wealth

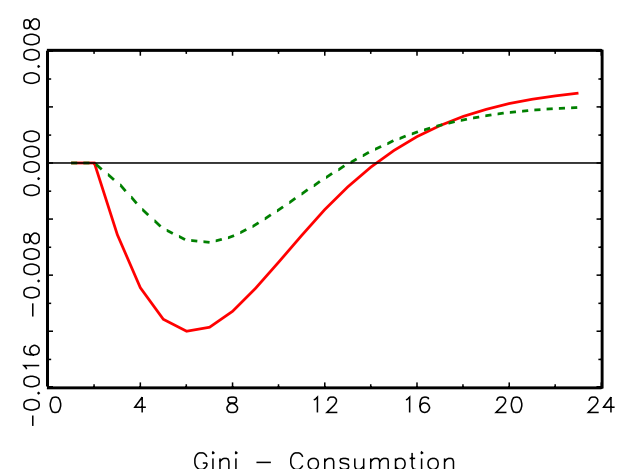

Gini - Consumption

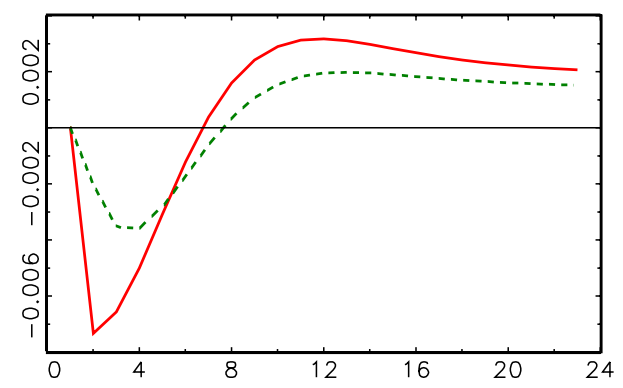

Figure A.4: Sensitivity Analysis: Share of Rule-of-Thumb Consumers. Impulse responses of Gini Coefficients (percent deviations) - Abscissa: Periods after shock in $t=2$. 
Gini - Gross Market Inc.
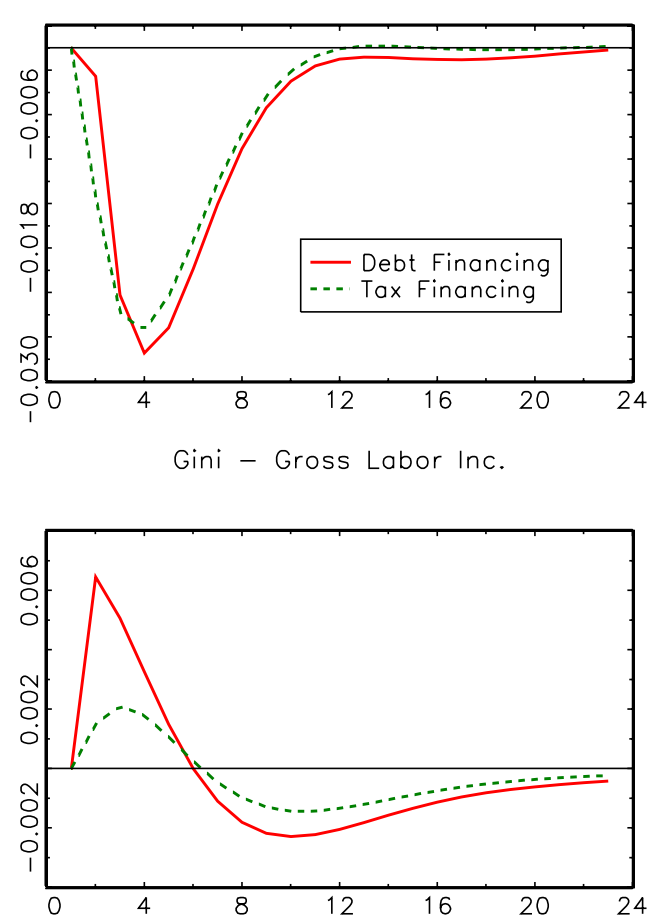

Gini - Wealth
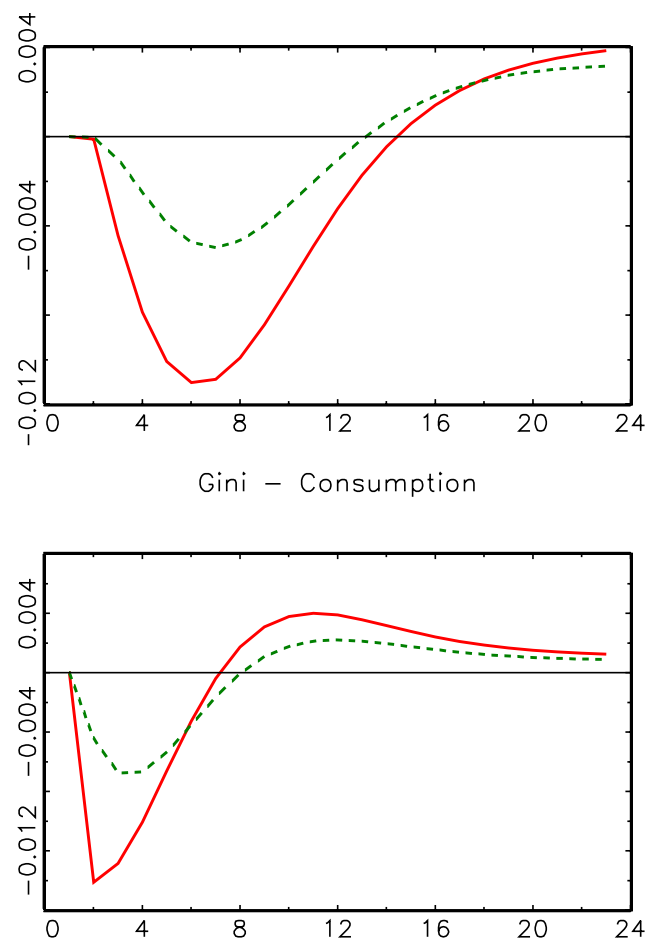

Figure A.6: Sensitivity Analysis: Portfolios. Impulse responses of Gini Coefficients (percent deviations) - Abscissa: Periods after shock in $t=2$. 
IR-CEC (Type 1, Ric)

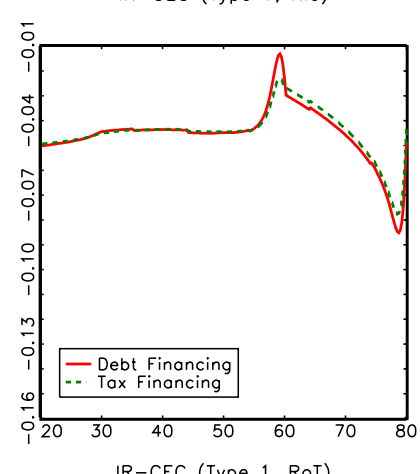

(Type 1, RoT)

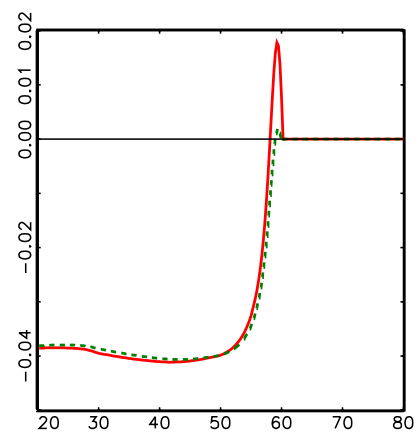

VOL-CEC (Type 1, Ric)
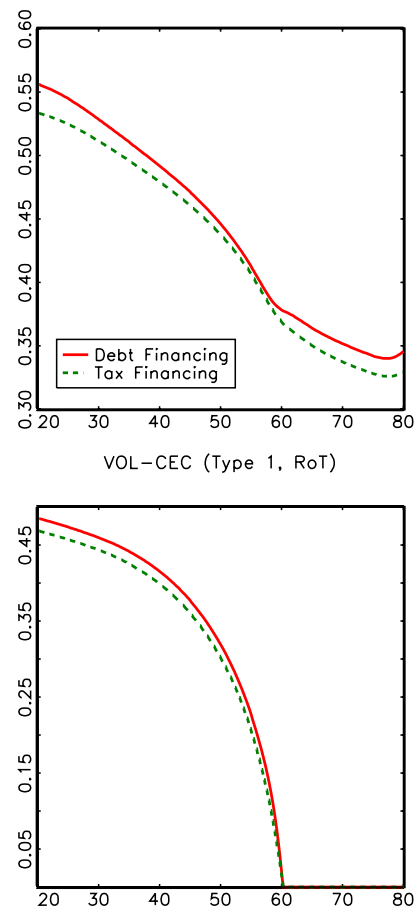

IR-CEC (Type 2, Ric)
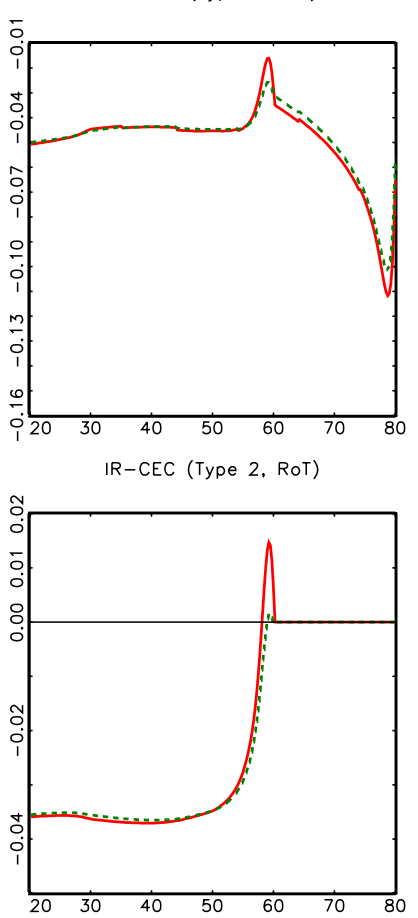

VOL-CEC (Type 2, Ric)

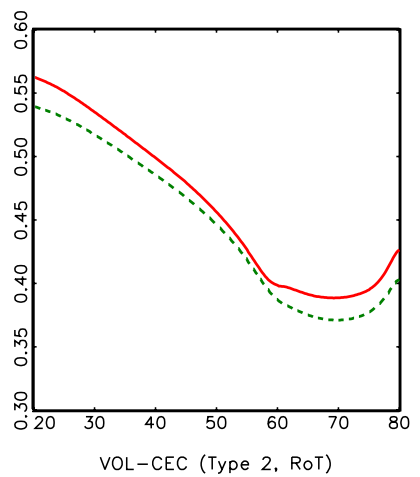

VOL-CEC (Type 2, RoT)

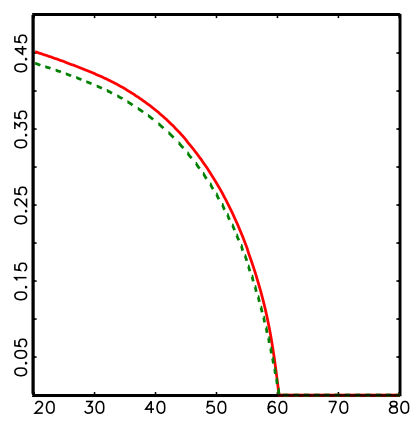

IR-CEC (Type 3, Ric)
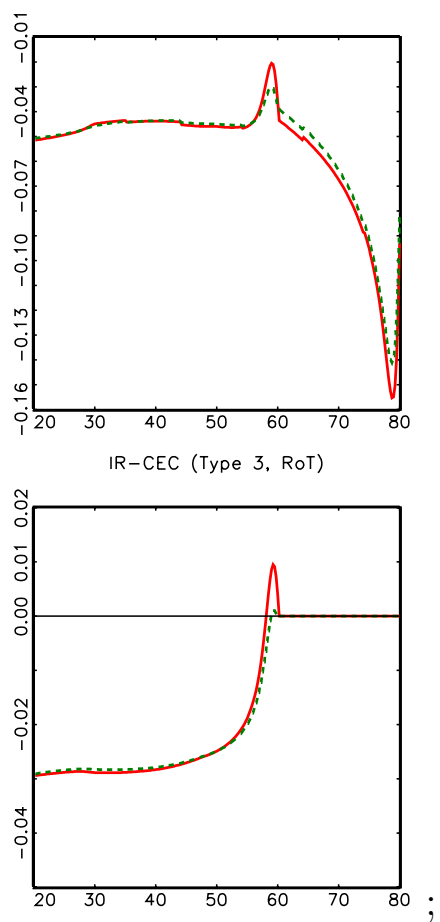

VOL-CEC (Type 3, Ric)
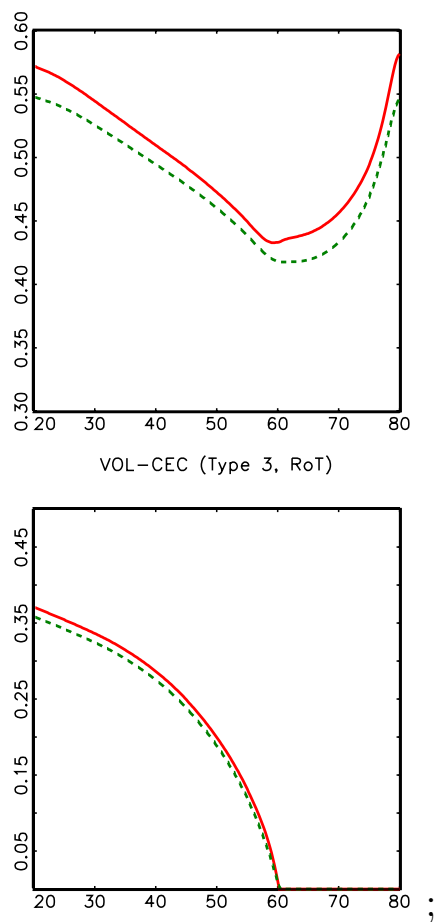

Figure A.7: Sensitivity Analysis: Portfolios. Impulse Responses and Volatilities for Consumption Equivalent Changes (CEC in \%) - Abscissa: Age in years. Types 1 to 3: Productivity types $j \in\{1,2,3\}$. 